\title{
Development and validation of a new adolescent self-report scale to measure loss of interest and pleasure: the anhedonia scale for adolescents (ASA)
}

Article

Accepted Version

Watson, R., McCabe, C., Harvey, K. and Reynolds, S. (2021) Development and validation of a new adolescent self-report scale to measure loss of interest and pleasure: the anhedonia scale for adolescents (ASA). Psychological Assessment, 33 (3). pp. 201-217. ISSN 1939-134X doi:

https://doi.org/10.1037/pas0000977 Available at https://centaur.reading.ac.uk/93361/

It is advisable to refer to the publisher's version if you intend to cite from the work. See Guidance on citing.

To link to this article DOI: http://dx.doi.org/10.1037/pas0000977

Publisher: American Psychological Association

All outputs in CentAUR are protected by Intellectual Property Rights law, including copyright law. Copyright and IPR is retained by the creators or other copyright holders. Terms and conditions for use of this material are defined in the End User Agreement. 


\section{www.reading.ac.uk/centaur}

\section{CentAUR}

Central Archive at the University of Reading

Reading's research outputs online 
Development and Validation of a New Adolescent Self-Report Scale to Measure Loss of Interest and Pleasure: The Anhedonia Scale for Adolescents (ASA)

\section{Accepted for publication in Psychological Assessment.}

CAmerican Psychological Association, [2020]. This paper is not the copy of record and may not exactly replicate the authoritative document published in the APA journal. Please do not copy or cite without author's permission.

\section{Rebecca Watson*1, Ciara McCabe, ${ }^{1}$ Kate Harvey, ${ }^{1}$ Shirley Reynolds ${ }^{1}$.}

${ }^{1}$ School of Psychology and Clinical Language Sciences, University of Reading.

*Corresponding author information: Rebecca Watson, School of Psychology and Clinical Language Sciences, University of Reading, RG6 7BE, UK (e-mail:

r.watson2@pgr.reading.ac.uk). Orchid ID: 0000-0002-3551-4461

Acknowledgements: The authors would like to thank school/college staff for their support and role in recruiting participants, as well as Dr Hannah Whitney for her clinical input, and Ihuoma Alichukwu for her assistance with research tasks.

Author Contributions: RW, CM and SR designed the study. RW oversaw the data collection and performed the analysis with input from KH. RW wrote the manuscript with input from all the authors (KM, CM and SR).

Conflict of Interest Statement: The authors declare no conflict of interest.

Ethical Statement: This research has been approved by the appropriate ethics committees and has, therefore, been performed in accordance with the ethical standards laid down in the 1964 Declaration of Helsinki and its later amendments.

Funding Statement: This study has been funded by an Economic and Social Research Council (ESRC) PhD studentship. 


\begin{abstract}
Anhedonia, the loss of interest and pleasure in previously enjoyable experiences, is a core symptom of depression and a characteristic of other mental health and physical health problems. Most self-report measures of anhedonia have been developed for use with adults and their suitability for adolescents is questionable. In this paper we describe the development and psychometric qualities of a new measure, the Anhedonia Scale for Adolescents (ASA), designed specifically for use with adolescents aged 11-18 years. Items were generated from in-depth qualitative interviews with depressed young people, and then reviewed by an independent group of young people and clinically qualified experts in adolescent mental health. After piloting the new scale $(n=66)$, we established the structural validity of the measure with two groups of young people using exploratory $(n=1057)$ and confirmatory $(n=1041)$ factor analysis. The final scale consisted of 14 items, with 1 general factor and 3 specific factors producing the best fit to the data, 1) Enjoyment, Excitement and Emotional Flattening (negatively framed); 2) Enthusiasm, Connection and Purpose (positively framed); 3) Effort, Motivation and Drive (negatively framed). The ASA had high test-retest reliability and converged with standardized measures of depression, negative symptoms of schizophrenia, pleasure and positive affect. Findings from these analyses provided evidence of incremental validity, as the ASA was a stronger predictor of clinical group (high vs. low depressive symptoms) than existing measures used to assess anhedonia. The ASA has potential as a new clinical and research tool to assess adolescent anhedonia.
\end{abstract}

Keywords: anhedonia, depression, adolescents, psychometrics, measurement, scale Public Significance Statement: In this study we developed and validated the Anhedonia Scale for Adolescents (ASA), a measure of anhedonia (loss of interest/pleasure) for adolescents. Results suggest that the ASA is a useful tool to assess anhedonia in adolescents. 


\section{Introduction}

Anhedonia, the loss of interest and pleasure in previously enjoyable experiences, is a core symptom of major depressive disorder (MDD), and a feature of a range of mental health problems including schizophrenia, substance misuse, and post-traumatic stress disorder (APA, 2013). Amongst adolescents, MDD is one of the most common mental health problems (Polanczyk et al., 2015) and is associated with high rates of recurrence during adulthood (Dunn \& Goodyer, 2006), increased risk of suicide (Hawton et al., 2012), and increased risk of long term adverse health, economic and social impacts (Clayborne et al., 2019). More than half of adolescents with depression meet diagnostic criteria for the symptom of anhedonia (Goodyer et al., 2017; Orchard et al., 2017) and anhedonia predicts poor treatment outcome in adolescents (McMakin et al., 2012).

Despite its adverse impact anhedonia is typically not targeted in psychological treatments of depression although there is increased interest in developing interventions that focus on reducing anhedonia and increasing positive affect (Craske et al., 2019; Dunn et al., 2019). The symptom of anhedonia is understood to be related to dysfunctional reward processing (RDoC Positive Valence System, (NIMH, 2011b, 2018; Rizvi et al., 2016), with increasing evidence suggesting that anhedonia consists of a number of different rewardrelated deficits, including the inability to pursue, experience or learn about pleasure/reward (Thomsen, 2015, Thomsen et al., 2015). Reward processing consists of several components or steps, known as wanting (appetitive/motivational), liking (consummatory/hedonic) and learning (predictions made about possible future rewards) (Berridge, 2003; Berridge \& Kringelbach, 2008, 2015), with further distinctions made between the anticipation of future rewards and the effort expended to receive a reward (e.g. Kring \& Barch, 2014). There is evidence to support differences in reward processing between depressed and non-depressed individuals (Halahakoon et al., 2020; Rizvi et al., 2016). Despite the accumulating body of 
research on reward processing in depression, it is not clear precisely which aspects of the reward process are the most disabling, and which distinctions are accessible to conscious awareness. Research on the Positive Valence System Scale (PVSS), developed to assess the NIHM's positive valence system domain of interest within RDoC initiative (Insel et al., 2010), found differences between PVSS scores for individuals with high and low depression symptom scores (on the PHQ-9), supporting the link between self-reported reward processing difficulties and depression (Khazanov et al., 2020). Anhedonia also features as a concept of 'loss' within the Negative Valence System (NIMH, 2011a) domain of RDoC, highlighting the complex, and still largely unknown nature of anhedonia within mental health. Therefore, in this paper we operationalise the concept of anhedonia as a broad loss of interest and pleasure (APA, 2013), which encompasses the absence of, or inability to experience consummatory and/or anticipatory pleasure, to feel positive, happy, connected, fulfilled and motivated to engage with the world; or to experience the desire to seek out positive and rewarding experiences. This absence or loss may in turn be accompanied by a sense of frustration with the inability to feel pleasure, and may lead to feelings of detachment and behavioural withdrawal.

Adolescence is a critical time for both the development of depression and for changes in reward-related processing (Forbes \& Dahl, 2012). In particular, adolescents are more likely than adults to seek out rewards (Shulman et al., 2016), to engage in risky behaviours (Steinberg, 2004), and to experience heightened responses to emotional cues (Casey et al., 2011; Somerville et al., 2010). Hyper-responsiveness in the brain reward system (i.e. striatum) during adolescence means that adolescents respond differently to rewarding stimuli than adults (Galvan, 2010). Despite generally increased reward seeking behaviour during this period, heightened depression rates (and therefore for many individuals reduced rewardrelated activity) leads to a greater disparity in reward-related functioning during adolescence 
than at other points in the lifespan (Forbes \& Dahl, 2012). The presentation of symptoms of depression in adults and adolescents may also be different. For example, Rice et al., (2019) found that vegetative and physical symptoms, such as fatigue, were more commonly reported by adolescents than adults. In addition, the way in which individual symptoms, such as anhedonia, are experienced may differ in adults and young people. Auerbach et al., (2017) suggested that the initial onset of anhedonia in young people is likely to be characterised by reduced energy and diminished motivation, and subsequently by behavioural withdrawal and broader features of anhedonia. In studies exploring real-life positive affect (Experience Sampling Methodology; ESM), adolescents with higher levels of depressive symptoms at baseline experienced fewer positive events and reported lower positive affect over the course of the study, but enjoyed pleasurable events 'in the moment'(consummatory) as often and as much as non-depressed adolescents (van Roekel et al., 2016). In an ESM study with adults, individuals meeting diagnostic criteria for major depressive disorder experienced blunted anticipatory and consummatory pleasure in comparison to healthy controls (Wu et al., 2017), suggesting possible differences in anhedonia based on age and/or clinical severity.

To better understand the experience and presentation of anhedonia in adolescents, assess the symptom, and develop new treatments that target anhedonia, sensitive and valid instruments are needed. The majority of scales to measure anhedonia have been developed for adults and therefore may not be optimal for the assessment of anhedonia during adolescence because of the key developmental changes that occur during this period (Forbes \& Dahl, 2012) and potential differences in how anhedonia may be experienced by adults and young people. Most self-report measures used to measure anhedonia have been devised to assess only consummatory aspects of anhedonia/ loss of pleasure and do not assess anticipatory or motivational anhedonia (e.g. the Chapman Physical Anhedonia Scale (CPAS)/Chapman Social Anhedonia Scale (CSAS), Chapman et al., 1976; Fawcett - Clark 
Pleasure Scale (FCPS), Fawcett et al., 1983; Snaith Hamilton Pleasure Scale (SHAPS); Snaith et al., 1995). In addition, of these consummatory measures, only the SHAPS (Snaith et al., 1995) has been validated for use with adolescents (Leventhal et al., 2015). Despite this some of the items are of arguable relevance to adolescents (i.e. pleasure from smelling flowers or bread). Although anhedonia is a core symptom of depression, when completed by adolescents, the SHAPS did not significantly correlate with the depression subscale of the Revised Child Anxiety and Depression Scale (RCADS) (Leventhal et al., 2015).

A number of more recently developed scales aimed to address both anticipatory/'wanting' and consummatory/'liking' aspects of pleasure or reward, e.g. the Anticipatory and Consummatory Interpersonal Pleasure Scale (ACIPS), (Gooding \& Pflum, 2014) and the Temporal Experience of Pleasure Scales (TEPS), (Gard et al., 2006) within a specific domain, i.e. a social or sensory reward experience, respectively. However, items in both the TEPS and ACIPS that were developed to capture 'wanting' deficits (i.e. imagining how something will taste) likely map onto the ability to 'imagine' future events in a positive way, a concept that is important, but arguably different to 'wanting'. Instead 'wanting' might align more closely with questions about motivation to attain those positive experiences or the willingness to expend effort to reach a reward (McCabe, 2018). The fact that motivational difficulties are a prominent part of adolescents' experiences of anhedonia (Watson et al., 2020) also suggests it is important to ask about this component when making a full assessment of anhedonia in this age group.

Gooding et al., (2016) made efforts to adapt the ACIPS for adolescents but took a 'top-down' approach to validity, eliminating obvious irrelevancies and changing language (e.g. replacing 'work' with 'school') rather than using an inductive approach by asking adolescents if the items captured their experience of social pleasure. Using a 'top down' approach may omit important aspects of adolescents' experiences. The Dimensional 
Anhedonia Rating Scale (DARS) (Rizvi et al., 2015) is a recent measure that assesses a broad range of reward-related components in depression (pleasure, interest, motivation and effort) and types of reward (i.e. hobbies, social, and sensory). Although this scale does assess motivational difficulties, item selection was based entirely on internal consistency and structural analyses with no assessment of their validity (Rizvi et al., 2015). In addition, the DARS might not be the best choice of measure for adolescents, as it requires participants to generate specific activities to rate. This requires cognitive effort and may challenge depressed adolescents, who have depression specific working memory problems (Fisk et al., 2019).

Currently therefore, because there is no psychometrically valid measure of anhedonia developed based on adolescents' own experiences, we aimed to develop a new brief symptom measure for this age group. We used a predominantly inductive approach to scale creation. Inductive methods are considered useful when there is uncertainty about the exact definition or dimensionality of a concept (Tay \& Jebb, 2017). This consideration applies to the measurement of anhedonia as there is considerable disparity in the literature regarding its conceptualisation (e.g. Forbes \& Dahl, 2012; Gorwood, 2008; Rømer Thomsen et al., 2015). Many procedures that are typically attributed to a theoretical-rational or deductive method (see Clark \& Watson, 2019) were also used to guide scale development, such as creating an item pool which is broader and more comprehensive than the theoretical view of the target construct. We followed a scale development process devised by Gehlbach and Brinkworth (2018) which focuses on establishing the construct validity of a scale by using an inherently collaborative approach, relying on the input of the target population in item construction; as well as specific questionnaire development guidance recommended by the Consensus-based Standards for the selection of health Measurement Instruments (COSMIN, Mokkink et al., 2018), which advocates using constructs and language generated through qualitative interviewing. 
Watson et al., (2020) conducted a qualitative study with young people about their experiences of anhedonia, which formed the basis of the new scale development. In line with the growing body of literature which suggests that anhedonia is a multifaceted construct (e.g. Rømer Thomsen et al., 2015), adolescents described experiencing a flattening of emotion, and a loss of pleasure and joy from life; as well as a lack of motivation, passivity, and increased effort to engage in activities. Furthermore, adolescents described losing a sense of connection or belonging, feeling detached from people and the world around them, as well as struggling to find a purpose or to 'see the point' in what they were doing. The findings from this study suggested that most self-report measures used to assess anhedonia may be too narrow, and only capture a part of adolescents' subjective experiences. Therefore, quotes from the qualitative interviews were used as the basis of item generation, and items were piloted and refined with the help of young people and clinical and academic experts. The remaining items were then subjected to psychometric scrutiny; the structural validity of the scale was examined and confirmed in two large community sub-samples of young people; and the re-test reliability of scale scores was examined in a subsample of participants.

Given that anhedonia is a clinical construct that is considered to be state like in the context of depression (e.g. Loas, 1996), we anticipated that the new scale would correlate more strongly with measures of relevant clinical disorders than with personality traits or traitlike measures of related constructs. We predicted that the new Anhedonia Scale for Adolescents (ASA) would be positively correlated with self-report measures of affective disorders for which anhedonia is a distinct feature (i.e. depression, negative symptoms of schizophrenia) as well as with low levels of positive affect, and reduced reward processing (i.e. pleasure, motivation). We expected the ASA to be less strongly correlated with disorders in which anhedonia is not a symptom (i.e. anxiety) or with different constructs in which anhedonia is not a direct feature (i.e. behavioural inhibition, negative affect, impulsivity- 
related behavioural approach). Furthermore, we expected that the ASA would be a stronger predictor of depressive status (high vs. low depressive symptoms) than existing validated measures used to assess anhedonia in adolescents.

\section{Method}

\section{Scale Development}

Item pool development. Item content for the adolescent anhedonia scale (ASA) was generated from qualitative interviews with adolescents about their experiences of anhedonia (Watson et al., 2020). In this qualitative study 34 adolescents recruited from a clinical service or the community, who had either a depressive diagnosis or elevated depression symptoms respectively, discussed their experiences of losing interest and pleasure. In line with current theoretical understanding of anhedonia as a multidimensional construct (e.g. Berridge \& Kringelbach, 2008), adolescents responded to open ended questions about losing consummatory aspects of enjoyment and pleasure, changes in anticipation and future pleasure, as well as differences in motivation and effort. As is customary in qualitative research, interviews were guided by adolescents' own experiences, with further prompt questions used to elicit a greater depth of response. Adolescents experiences were analysed using thematic analysis (Braun \& Clarke, 2006) and captured four main aspects of adolescents' experiences: 1) Experiencing a loss of joy and a flattening of emotion, 2) Struggling with motivation and active engagement, 3) Losing a sense of connection and belonging, 4) Questioning sense of self, purpose and the bigger picture. The first two themes were the primary aspects of adolescents' experiences, and the last two themes were the secondary aspects of these experiences.

An initial pool of 200 items was generated from statements made by young people who took part in the qualitative study. A thorough examination of existing self-report scales 
was also conducted and used to inform the selection and wording of candidate items (Boateng et al., 2018; Clark \& Watson, 1995). Duplicate items were eliminated, and the remaining items were categorised into the themes identified in Watson et al., (2020). Five adolescents commented on the relevance, acceptability and face validity of each questionnaire item. The 40 most preferred items that reflected all key features of each theme were then selected for further feedback.

Expert and adolescent feedback. Six clinical experts (i.e. clinical psychologists and child and adolescent psychiatrists working in UK publicly funded Child and Adolescent Mental Health services were asked about their experience of working with young people experiencing anhedonia. This included a discussion of the key themes from Watson et al., (2020). Some experts also gave specific feedback on the draft items. Their feedback confirmed that the items were relevant to their clients, but also highlighted conceptual overlap between anhedonia and other clinical constructs (e.g. low mood, hopelessness) and between concepts within the questionnaire (i.e. enjoyment, anticipation and motivation). All draft items were then reviewed by ten young people, to assess their face validity, readability and overall impression. When asked to rate different response options (i.e. agreement versus frequency) young people preferred the frequency scale and this was also considered to be the most clinically useful. Four points were selected to ensure that the available options were distinct. Based on the feedback from experts and young people several items were reworded and some items were removed. For example, some items that related to more abstract concepts e.g. "being on autopilot" were not readily understood, and some items "I distracted myself from my feelings" were considered too vague, and could relate to a number of experiences. Lastly, some items assessing a specific concept e.g. effort were preferred over the wording of other items [see Supplementary Material Section B for further details]. This resulted in a draft scale of 30 items for piloting. 


\section{Participants}

Recruitment and Pilot Sample. Fifteen schools and colleges in the South of England were invited to take part in the study; seven responded and five agreed to take part. Students from three classes in one publicly funded comprehensive school $(\mathrm{n}=66 ; \mathrm{M}$ age $=12.0, \mathrm{SD}=$ $1.7 ; 45.5 \%$ female, $81 \%$ White British) took part in the pilot study.

Main Sample. The main study ( $=2098$ after 27 participants with more than $25 \%$ missing data on the ASA were removed) consisted of students from the remaining classes in the pilot comprehensive high school $(n=455)$, a second mixed-sex comprehensive high school $(n=211)$, two selective single sex schools (girls $n=651$, boys $n=600)$ and students in psychology classes in a mixed-sex college for young people aged $16-18,(n=181)$. Participants in the main study were aged $11-18$ years $(M=14.39, \mathrm{SD}=2.07)$, with $55.5 \%$ females, and 50.0\% white British, 5.5\% white non-British; $34.1 \%$ Asian, $2.4 \%$ Black background, $6.5 \%$ mixed background, $1.5 \%$ other. Sixty five percent of invited participants took part. Based on the index of free school meals (percentage of pupils eligible for free school meals at any time in the past 6 years; average in England 27.7\%), the two comprehensive schools had a percentage close to the national average $(21.3-21.4 \%)$ and the two single sex schools had a percentage much lower than the national average $(2.4-3.1 \%)$ (GOV.UK, 2020). These data were not available for the college students.

To explore and confirm the structure of the new scale, the sample was split into two groups defined by the questionnaire pack they completed (Pack A or Pack B; see procedure). The two samples did not differ on mean age, $\mathrm{t}(2090)=.539, \mathrm{p}>.05$ or gender $\mathrm{X}^{2}(1)=1.904$, p >.05 [see Supplementary Material Section D for ASA descriptive statistics by age and gender].

\section{Procedure}


Institutional ethical approval for the study was granted from the University Research Ethics Committee. Parental opt-out consent and participant opt-in assent was obtained for young people under 16, and participant opt-in consent was obtained for participants aged 16 and over. Participants were given questionnaire Pack A or Pack B which were assigned randomly to each participant (see below for details). Questionnaires were split into Pack A or B to reduce participant burden. Pack A and Pack B both contained the new anhedonia questionnaire and written feedback questions, demographic questions (age, gender, and ethnicity) and an adolescent specific measure of depression, the Mood and Feelings Questionnaire (MFQ; Angold et al., 1987). Participants also completed other questionnaires (depending on whether they received Pack A or B), which were randomly ordered (to reduce bias). Participants completed the questionnaires in their classroom/lecture hall during the school/college day. Participants in the pilot sample completed 30-items, and participants in the main sample completed the 32-item revised items plus 5 supplementary reversed items. When questionnaires had been completed participants were provided with information on sources of support for mental health. Consenting participants were entered into a prize draw to win an online voucher.

\section{Measures}

\section{Completed by all participants:}

The Anhedonia Scale for Adolescents (ASA). The ASA is a self-report scale of adolescents' experiences of anhedonia. See the results section for refinement of items, and Supplementary Material [Section B]. Participants rated each item on a four-point Likert scale from $0-3$; never, sometimes, often, always, in respect to the past two weeks. Positively framed items are reverse scored, and a higher score indicates more anhedonia. Participants answered an open question, 'over the past two weeks, has anything stopped you from feeling positive?' Subsequently, participants were asked to rate on a four -point Likert scale 'over the 
past two weeks, how often did you not feel positive? Response options included: none, several days, more than half the days, and almost every day.'

The Mood and Feelings Questionnaire (MFQ: (Angold et al., 1987) is a 33-item self-report scale of depression symptoms for adolescents. It has good psychometric properties (Burleson Daviss et al., 2006). A cut-off score of 27 and above has been identified as the difference between clinical and non-clinical levels of depressive symptoms (Wood et al., 1995). Each item is rated on a three-point Likert scale from 0, not true, to 2, true, (internal consistency ordinal $\alpha .97)$.

\section{Questionnaire Pack A:}

The Snaith Hamilton Pleasure Scale (SHAPS; (Snaith et al., 1995) is a 14-item selfreport scale of consummatory anhedonia that has been validated for use with adolescents (Leventhal et al., 2015). Each item is rated on a four-point Likert scale ranging from $0=$ strongly agree, $3=$ strongly disagree (Franken et al., 2007). A higher score indicates less pleasure (internal consistency ordinal $\alpha .91$ ).

The Behavioural Inhibition and Behavioural Activation Scales (BISBAS; Carver \& White, 1994) is a 24-item self-report dispositional/ personality measure of two motivational systems: the behavioural approach (BAS) and behavioural inhibition (BIS) systems. The Behavioural Approach system scales are divided into 3 subscales assessing different aspects of 'incentive sensitivity' (Carver \& White, 1994), in particular the "fun-seeking” subscale is known to have elements of dysfunctional impulsiveness (e.g. Franken et al., 2005), whereas high "reward responsiveness" has been shown to uniquely predict internalising disorders, wellbeing and affect regulation (Taubitz et al., 2015). Each item is rated on a four-point Likert scale from 1, very true, to 4, very false. One item ("drive" subscale) elicited some confusion in the pilot study (item 21) therefore this item was therefore removed from analyses. A higher score indicates lower behavioural activation (internal consistency BAS 
ordinal $\alpha .86$; BAS drive ordinal $\alpha .78$; BAS fun .61; BAS reward responsiveness ordinal $\alpha .79$ ) and lower behavioural inhibition (internal consistency: BIS ordinal $\alpha .83$ ).

The Positive and Negative Affect Scale - Child Version (PANAS-C: Ebesutani et al., 2012) is a 10-item measure of current positive (5-items e.g. cheerful) and negative affect states (5-items e.g. sad) adapted for children and adolescents (Watson \& Clark, 1994). Each item is rated on a five-point Likert scale from 1, very slightly or not at all, to 5, extremely. A higher score indicates greater intensity of emotional experience (internal consistency, positive: ordinal $\alpha .91$, negative ordinal $\alpha .85$ ).

\section{Questionnaire Pack B:}

The Anticipatory and Consummatory Interpersonal Pleasure Scale-Adolescent version (ACIPS-A; Gooding et al., 2016; Gooding \& Pflum, 2014) is a 17-item self-report scale of anticipatory and consummatory social pleasure, adapted for use with adolescents. Each item is rated on a four-point Likert scale from 1, very true, to 4, very false. A higher score indicates greater experience of pleasure (internal consistency ordinal $\alpha .93$ ).

The Self-Evaluation of Negative Symptoms (SNS; Dollfus et al., 2016) is a 20-item self-report measure of negative symptoms of schizophrenia, namely social withdrawal, diminished emotional range, alogia, avolition and anhedonia. One anhedonia item was not administered to adolescents due to its sexual content. The scale consists of 2 factors reflecting 1) apathy (amotivation, anhedonia, alogia, asociality) and 2) emotional (diminished emotional range). Each item is rated on a three-point Likert scale from 0, strongly disagree, to 2, strongly agree. A higher score indicates the presence of more negative symptoms (internal consistency ordinal $\alpha .94$; apathy factor ordinal $\alpha .94$; ordinal $\alpha .63$ emotional factor).

The Generalised Anxiety Disorder Scale (GAD-7; Spitzer et al., 2006) is a 7-item self-report scale of anxiety symptoms developed for adults but validated for use in adolescents. Each item is rated on a 4-point Likert scale from 0, not at all, to 3, nearly every 
day. A greater score indicates the presence of more anxiety. This scale was only included in the pilot sample and was then replaced with a child and adolescent specific measure of child and adolescent anxiety (RCADS; Chorpita et al., 2000).

The Revised Child Anxiety and Depression Scale (RCADS) is a 47-item child specific self-report measure of anxiety and depression (Chorpita et al., 2000; Spence, 1997). Each item is rated on a four-point scale 0 - 3 (never, sometimes, often, always). Unlike the GAD-7, this scale enables different types of anxiety to be assessed. The OCD subscale (6 items) was administered in Pack A, (internal consistency; OCD ordinal $\alpha .86$ ). The GAD (6 items) and PANIC (9 items) subscales were administered in Pack B, (internal consistency; Panic ordinal $\alpha .93$; GAD ordinal $\alpha .90$ ). This scale was added after the initial pilot.

\section{Statistical Analysis Plan}

Data handling and scale refinement. All participants responded to closed and openended feedback questions, and items were reworded or removed at each stage in line with participants' feedback in several iterations. Participants with $>25 \%$ missing data on the primary scale (ASA) were removed from all data analyses (Sample A, $n=10$; Sample B, $n=$ 17), and participants with $>25 \%$ data missing on legacy instruments were removed from subsequent analyses where applicable (i.e. correlation between ASA and SHAPS) (Field, 2013). Item variance was examined for the ASA. Individual scale items were treated as endogenous ordinal data, and item-level correlations were calculated based on polychoric correlation matrices. Predictive mean matching was used to simulate values for item-level analyses with missing data $<25 \%$ on the ASA. Total scale and subscale scores were treated as continuous data. When calculating total and subscale scores, if $<25 \%$ data was missing on measures, a total score or subscale score was created using an average score multiplied by the number of items in the scale/subscale. [See Supplementary Material Section A for flow chart of the scale development and validation process]. 
Exploring the factor structure. Subsample A $(\mathrm{n}=1057)$ was used for Exploratory Factor Analysis (EFA) using R studio (Psych package) based on polychoric correlations (see Revelle, 2020). Parallel analysis (Horn, 1965), the scree plot of actual and simulated eigenvalues, and Velicer's (1976) Minimum Analysis Partial (MAP) analysis were run to determine the number of factors to retain. EFA with Principal Axis Factoring (PAF) was conducted due to multivariate non-normality, with a factor loading of .3 considered acceptable for loading onto a factor, with a preference for loadings $>.4$ and cross loading $<.32$ (Tabachnick \& Fidell, 2014). An initial PAF was run to eliminate items based on low communalities and/or lower factor loadings, whilst also retaining items within each subcategory of the original qualitative themes [see Supplementary B]. A further PAF was run with 14 items. All plausible factor solutions were explored using the following model fit indices: the Tucker-Lewis incremental fit index (TLI; Tucker \& Lewis, 1973; (>.9 acceptable fit; >.95 good fit; >.97 very good fit) and the root means square error of approximation (RMSEA; Steiger, Shapiro \& Brown, 1985; <.08, acceptable fit, <.05 good fit), and the percentage of variance explained ( $>50 \%$ acceptable) (Mokkink et al., 2018).

Confirming the factor structure. Subsample B $(\mathrm{n}=1041)$ was used for Confirmatory Factor Analysis (CFA) using Weighted Least Square Mean and Variance Adjusted (WLSMV) estimators due to ordinal data with multivariate non-normality (Flora \& Curran, 2004) in R studio (package Lavaan). Robust model fit indices for the CFA included: robust chi square/degree of freedom ( $<=3$, good fit); TLI (Tucker \& Lewis, 1973) and confirmatory fit index (CFI; Bentler, 1990), with values approaching 1 implying a good model fit (>.9 acceptable fit; >.95 good fit; >.97 very good fit); and RMSEA (Steiger et al., 1985) and standardised root mean square residual (SRMR), with values approaching zero indicating a good model fit (<.08, acceptable fit, <.05 good fit) (e.g. Kline 2005; Hooper et al., 2008). 
Hierarchical bifactor models were run to establish if the ASA was better explained by a general factor (representing the broad target construct) and specific factors (representing narrower sub constructs). In bifactor models it is assumed that general and specific subfactors are orthogonal, with the general factor accounting for associations between the group factors (Reise, 2012). Therefore, in the bifactor models covariances between the general and specific factors were constrained to be orthogonal.

Internal consistency and test re-test reliability. Internal consistency reliability for items in the full ASA scale and subscales was conducted using Cronbach's alpha based on polychoric correlations and omega statistics in R studio (psych package). Test-retest reliability $(\mathrm{n}=200)$ was assessed and Intra-Class Correlations (ICC) were run in SPSS based on a two-way mixed effects model as recommended (Koo \& Li, 2016).

Convergent and discriminant validity. Convergent and discriminant validity were established using Spearman's rank order correlations (due to multivariate non-normality) in SPSS between total scores on the ASA and related constructs. To compare the statistical difference in the strength of correlations between the ASA and convergent and discriminant measures we used an online calculator developed by Lenhard and Lenhard (2014). To facilitate this analysis, scales were reverse scored where necessary i.e. a positive correlation equates to low positive affect (PA), high negative affect (NA), low behavioural activation (BAS), high behavioural inhibition (BIS), low pleasure (ACIPS and SHAPS), high depression (MFQ), high schizophrenia symptoms (SNS) and high anxiety (RCADS). To further understand ASA' nomological network, multiple hierarchical step-wise linear regressions were run in SPSS to examine how much variance of the ASA was explained by related legacy constructs (convergent measures). Correlations were entered into the model in accordance with the strength of the correlation coefficient (highest to lowest). 
Incremental and predictive validity. To test for incremental validity, hierarchical logistic regression was run in SPSS to determine whether ASA responses predicted membership of the 'depressed' group (based on a cut-off score of 27 on the MFQ; Wood et al., 1995) above and beyond alternative measures used to assess anhedonia), the SHAPS (Snaith et al., 1995) and the ACIPS-A (Gooding et al., 2016). Multicollinearity indices of tolerance and variance inflation factor cut offs were above 0.1 and less than 10 , respectively (Field, 2013). To test for predictive validity, simple logistic regression was used to establish whether ASA scores at time point 1 were a significant predictor of 'depressed' group status at time point 2 .

\section{Results}

\section{Scale Feedback and Item Refinement}

Feedback and scale revision (first iteration). In the pilot study $(\mathrm{n}=66)$, participants provided written feedback on the draft Anhedonia Scale for Adolescents in respect of 1) the questionnaire instructions (100\% of those who responded said they understood); 2) understanding of items ( $86 \%$ of those who responded understood all items); and 3) suggested changes to the measure (95\% of those who responded did not suggest changes). We worked collaboratively with a clinical expert and a young person who was a member of our research Patient and Public Involvement group (PPI) to use the adolescents' responses and feedback to reword and revise the questionnaire items. Suggested changes included making the scale content / items more positive. Five items were selected for reversal where it was possible to reverse the item without changing the integral content of the construct being measured (e.g. feeling connected vs. disconnected) rather than concepts which could not be reversed (e.g. feeling flat). The draft anhedonia scale correlated highly with the MFQ ( $r s=.8$ ), which indicated that some items may have been assessing general depression rather than anhedonia 
specifically. Therefore a few items were refined and made more specific, for example, "I could not be bothered to do anything [even if it would be fun]," resulting in a 32-item scale for further testing [see Supplementary Material Section B].

Feedback and scale revision (second iteration). Participants from the sixth-form college $(\mathrm{n}=181)$ completed the questionnaires and responded to written feedback on the questionnaire, finding the instructions (100\%) and items (91\%) easy to understand, and $94 \%$ making no suggestions for changes. A preliminary examination of the factor structure of the scale indicated that the reverse scored items clustered onto one factor. Therefore, to enable further exploration of the effect of valence in a larger sample of participants, reverse framed items were added to the end of the scale resulting in 37-items for further testing [see Supplementary Section B].

Feedback and item removal (third iteration). The remaining participants in Sample A $(n=906)$ and Sample B $(n=960)$ provided written feedback on the draft Anhedonia Scale for Adolescents; specifically, 1) the questionnaire instructions (99\% said they understood); 2) understanding of items (90\% understood all items); and 3) suggested changes to the questionnaire ( $80 \%$ did not suggest changes). Only 1 item was identified as 'not easy to understand' by $>1 \%$ of participants and was therefore removed from subsequent analysis. A further item was removed from subsequent analysis, as upon reflection, the double-barrelled nature of the item meant participants' responses could have related to one of two different concepts within the statement (Clark \& Watson, 2019). The remaining 30-items were retained to explore the factor structure.

\section{Exploring the Factor Structure in Subsample A}

The factor structure of the draft 30 item questionnaire was explored using data from 1057 participants who had completed Pack A. Participants used all response options for every item (i.e. never to always). Furthermore, all items had a standard deviation $<.5$, and no 
items had significant skew or kurtosis (z-scores < 3.29; Tabachnick \& Fidell, 2014). The Kaiser-Meyer-Olkin (KMO) measure verified the sampling adequacy for the analysis (.97) and Bartlett's Test of Sphericity was significant $(\mathrm{p}<.001)$, indicating the adequacy of this sample for factor analysis.

Initial exploration of the factor structure and item reduction. To determine the number of factors to retain, a parallel analysis (Horn, 1965) was run which suggested retaining 7 factors. The scree plot of actual and simulated eigenvalues was also examined, which displayed one large factor and a break after 3 or 4 factors for the actual data, with 3 factors clearly visible above the line for simulated data. Velicer's (1976) Minimum Average Partial (MAP) analysis was also run and suggested retaining a minimum of 3 factors. [See Supplementary Material Section C for further details].

Principal Axis Factoring with an Oblique Promax rotation (due to likely correlation between factors) (de Winter \& Dodou, 2012) was run with a 7 and 3 factor solution explored. The 7-factor solution, in line with results of the parallel analysis, resulted in multiple items loading <.4 onto a factor, and a Heywood case suggesting possible over-extraction. Next, in line with the scree plot of actual and estimated eigenvalues and the MAP analysis, a 3-factor solution was explored. Almost all items loaded $>.4$ on to a factor and no items cross loaded $>.4$ onto a second factor. This produced a theoretically salient solution, with factors representing 1) affective elements of anhedonia, 2) motivational and effortful aspects, and 3) positively framed items which reflected a broader sense of purpose and meaning. Therefore the 3-factor solution was selected to facilitate item removal within dimensional categories [see Supplementary Material section B].

In order to produce a brief scale which reflected all elements of adolescents' experiences, items were reduced from 30 to 14 based on low communalities and factor loadings. The removal of items was completed in conjunction with information regarding 
content validity to ensure items were retained that represent each important aspect of the conceptual content (Flora \& Flake, 2017) i.e. we wanted to ensure some items were retained from every important concept identified in Watson et al., (2020) [see Supplementary Material Section B]. We also took into account any specific feedback from participants about particular items during item selection. After item removal, 14 items were retained for further exploration; 8 items reflected the subcategories of the 2 primary themes, 1) 'experiencing a loss of joy and a flattening of emotion', and 2) 'struggling with motivation and active engagement,' and 6 items reflected concepts in the secondary themes, 3) 'losing a sense of connection and belonging', and 4) 'questioning sense of self, purpose and the bigger picture' [see Supplementary Material sections B].

Further evaluation of the factor structure. Parallel analysis, the scree plot of actual and simulated eigenvalues, and Velicer's MAP analyses were re-run with the remaining 14items, with a 4, 2 or 3 and 1 factor solution identified, respectively [see Supplementary Material Section C]. All four potential solutions were re-examined using PAF with the 4 factor solution resulting in a theoretically meaningful distinction between the 'anticipatory' items (looking forward/excitement) and both the a) 'motivational and effort' based items, b) the 'enjoyment in the moment, detachment and lack of affect' items, as well as the positively framed items about 'purpose, meaning and wellbeing' factors identified in the initial factor analysis. All items loaded $>.4$ onto a principal factor and cross loaded $<.32$ onto a subsequent factor (see Table 1). The 3-factor solution clustered items in the same way as the 4-factor solution, but with the anticipatory items loading on the 'enjoyment, detachment, lack of affect' factor, with all items loading $>.4$ onto a factor and cross loading $<.32$. The 2 -factor solution produced factors separated based on valence (positive vs. negative) with all items loading >.4 and cross loading <.32; and the 1 factor solution also produced a solution with all items loading $>.4$ on the factor. 
Fit indices for the $1-4$ factor solutions were compared (see Table 3). The 3 and 4 factor solution produced an acceptable to good fit to the data, and the 1 and 2 factor solutions produced a low to acceptable fit to the data (see statistical analysis plan for recommended cut-offs). The 3-factor solution produced a good fit to the data, explaining $61 \%$ of the variance, 1) Enjoyment, Excitement and Emotional Flattening (34\%), 2) Enthusiasm, Connection and Purpose (14\%), and 3) Effort and Motivation (13\%), with moderate correlations between factors $(.62-.75)$. The 4-factor solution had the best fit to the data explaining $62 \%$ of the variance, and produced the most theoretically meaningful solution with separate factors for: 1) Enjoyment, Flattening and Detachment (25\% variance), 2) Purpose, Connection and Enthusiasm (13\% variance) (positively framed), 3) Effort and Motivation (13\% variance), 4) Excitement and Anticipation (11\% variance). The correlation between factors was moderate to high $(.62-.79)$, therefore it was important to test whether a more parsimonious solution would produce an equal or favourable fit to the data in another sample (Sample B).

Examining the impact of positively and negatively framed items. As anticipated, the positively framed items clustered onto one factor in the multi-factorial solutions. Therefore, it was important to establish if these items would cluster when they had the same valence as the rest of the items in the scale using Confirmatory Factor Analysis (CFA). Data was analysed from 916 young people for whom the negatively framed counterparts of the positively framed items were collected. Using CFA (WLSMV), the 2 - 4 factor solutions produced an acceptable to good fit to the data when the positively framed items (i.e. 'enthusiastic') were reversed (i.e. 'no enthusiasm') [see Table 2]. Therefore, it is likely that items in the original analysis clustered based on content as well as valence (positive/ negative framing). In line with adolescents' and experts' feedback, and to make sure that completing the scale did not 
induce a negative mood state in young people, we decided to retain the positively framed items rather than their negatively framed counterparts. 
Table 1. Factor Loadings for the 14-item Anhedonia Scale for Adolescents (ASA) 3 Factor Solution

EFA

F2 F3

\section{FACTOR 1 - Enjoyment, Excitement and Emotional Flattening}

I should have been enjoying things, but I couldn't

$\begin{array}{llll}\mathbf{0 . 8 2} & -0.01 & 0.02 & \mathbf{. 7 7 8} \\ \mathbf{0 . 8 0} & -0.11 & -0.01 & \mathbf{. 6 4 4}\end{array}$

I pretended things excited me, but actually I found them boring ${ }^{1}$

I felt detached from other people

Nothing felt fun or enjoyable

$\begin{array}{llll}\mathbf{0 . 7 6} & 0.10 & -0.08 & \mathbf{. 7 5 8}\end{array}$

I did not feel any emotion ${ }^{1}$

0.73

0.07

$0.09 \quad \mathbf{8 3 7}$

Nothing made me feel excited

0.69

0.05

$-0.01$

.737

I couldn't see myself enjoying things in the future

0.66

$\begin{array}{ll}0.12 & 0.09\end{array}$

.851

$\begin{array}{lllll}\mathbf{0 . 6 1} & 0.18 & 0.05 & \mathbf{. 6 4 4}\end{array}$

Internal Reliability [Sample A, $\alpha .92, \omega .93$; Sample B, $\alpha .91, \omega .91$ ]

FACTOR 2 - Enthusiasm, Connection and Purpose

I felt connected to the world around me (R)

I felt enthusiastic (R)

I felt like my life had meaning and purpose (R)

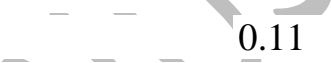

0.11

0.74

$-0.09$

.757

0.07

$\mathbf{0 . 7 0}$

0.21

.760

Internal Reliability [Sample A, $\alpha .79, \omega .80 ;$ Sample $B, \alpha .79, \omega .79$ ]

\section{FACTOR 3 - Effort, Motivation and Drive}

I had no motivation to get started on things

I did not want to do anything ${ }^{1}$

$\begin{array}{ll}-0.03 & 0.09\end{array}$

0.78

.731

Everything felt like a lot of effort to do

0.05

0.02

0.68

I did not look forward to anything*

0.36

$-0.11$

0.51

.723

Internal Reliability [Sample A, $\alpha .84, \omega .80$; Sample B, $\alpha .83, \omega .83$ ]

$\begin{array}{lll}\mathbf{0 . 5 7} & 0.07 & 0.26\end{array}$

Total Reliability - [Sample A, $\alpha .94, \omega .95$; Sample B, $\alpha .93, \omega .95]$

Note. $\mathrm{EFA}=$ Exploratory Factor Analysis (Principal Axis Factoring); CFA = Confirmatory Factor Analysis (WLSMV; standardised loadings); F1 = Enjoyment, Excitement and Emotional Flattening; F2 = Enthusiasm, Connection and Purpose, F3 = Effort, Motivation and Drive. Loadings >.4 in bold. $\mathrm{R}=$ Reverse Scored. ${ }^{1}$ Slight amendment to item wording to improve clarity and simplicity. *Item "I did not look forward to anything" initially included in Factor 1 in the EFA for Sample A and then in Factor 3 in the CFA for Sample B based on factor loadings and omega statistics. [See Supplementary Material Section $\mathrm{C}$ for further details and factor diagrams]. 
Table 2. Factor Loadings for the 14-item Anhedonia Scale for Adolescents (ASA) 4 Factor Solution

F1 $\quad$ F2 $\quad$ F3 $\quad$ F4

\section{FACTOR 1 - Enjoyment, Emotional Flattening and Detachment}

I should have been enjoying things, but I couldn't

I felt detached from other people

I pretended things excited me, but actually I found them boring ${ }^{1}$

Nothing felt fun or enjoyable

I couldn't see myself enjoying things in the future

I did not feel any emotion ${ }^{1}$

$\begin{array}{lllll}\mathbf{0 . 8 6} & 0.02 & 0.08 & -0.10 & \mathbf{. 7 8 5} \\ \mathbf{0 . 8 0} & 0.14 & -0.03 & -0.10 & \mathbf{. 7 6 5} \\ \mathbf{0 . 7 6} & -0.09 & 0.03 & 0.01 & \mathbf{. 6 5 1} \\ & & & & \\ \mathbf{0 . 5 0} & 0.06 & 0.07 & 0.30 & \mathbf{. 8 4 7} \\ \mathbf{0 . 4 8} & 0.19 & 0.06 & 0.14 & \mathbf{. 8 0 4} \\ \mathbf{0 . 4 5} & 0.04 & -0.04 & 0.32 & \mathbf{. 7 4 4}\end{array}$

Internal Reliability [Sample A, $\alpha .90, \omega .89$; Sample B, $\alpha .90, \omega .89$ ]

\section{FACTOR 2 - Connection, Purpose, and Enthusiasm}

I felt connected to the world around me (R)

I felt enthusiastic (R)

I felt like my life had meaning and purpose (R)

$\begin{array}{llll}0.14 & \mathbf{0 . 7 7} & -0.06 & -0.07\end{array}$

$\begin{array}{llll}-0.13 & \mathbf{0 . 6 9} & 0.19 & 0.09\end{array}$

.757

$\begin{array}{lllll}0.05 & \mathbf{0 . 6 5} & 0.00 & 0.01 & \mathbf{. 7 2 9}\end{array}$

Internal Reliability [Sample A, $\alpha .79, \omega .79$; Sample B, $\alpha .79, \omega .79$ ]

\section{FACTOR 3 - Effort and Motivation}

I had no motivation to get started on things

I did not want to do anything ${ }^{1}$

$\begin{array}{lllll}-0.01 & 0.10 & \mathbf{0 . 8 1} & -0.05 & \mathbf{. 7 6 0} \\ 0.03 & 0.02 & \mathbf{0 . 6 7} & 0.02 & \mathbf{. 6 8 4} \\ 0.29 & -0.10 & \mathbf{0 . 5 2} & 0.07 & \mathbf{. 7 5 2}\end{array}$

Everything felt like a lot of effort to do

0.29

$-0.10$

$\mathbf{0 . 5 2} 0.07$

.752

Internal Reliability [Sample A, $\alpha .80, \omega .78 ;$ Sample B, $\alpha .77, \omega .78$ ]

\section{FACTOR 4 - Excitement and Anticipation}

I did not look forward to anything

Nothing made me feel excited
0.13

0.24
0.01

0.07

0.15

$-0.04$

0.64

0.64

.825

.863

Internal Reliability [Sample A, $\alpha .86, \omega .76$; Sample B, $\alpha .83, \omega .76$ ]

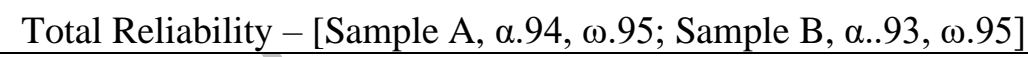

Note. EFA = Exploratory Factor Analysis (Principal Axis Factoring); CFA = Confirmatory Factor Analysis (WLSMV; standardised loadings); F1 = Enjoyment, Emotional Flattening and Detachment; F2 = Connection, Purpose, and Enthusiasm, F3 = Effort and Motivation, F4 = Excitement and Anticipation. ${ }^{1}$ Slight amendment to item wording to improve clarity and simplicity. Loadings $>.4$ in bold. $\mathrm{R}=$ Reverse Scored. [See Supplementary Material Section C for further details and factor diagrams]. 


\section{Confirming the Factor Structure in Subsample B}

The factor structure identified in Subsample A was confirmed with data from participants who completed pack B $(n=1041)$ using Confirmatory Factor Analysis (CFA) (WLSMV) with robust model fit indices reported. The KMO (.95) and Bartlett's Test of Sphericity $(\mathrm{p}<.001)$ indicated that the sample was adequate for factor analysis.

Fit indices for 1-4 factor solutions. The 1-4 factor solutions identified in the EFA were confirmed, with the 3 and 4-factor solutions providing a very good fit to the data (see Table 3). The 1 and 2-factor solutions produced an acceptable to good fit to the data, indicating that a more parsimonious solution was not an equal or superior fit to the data.

Higher order CFA. Next, we tested a bi-factor CFA model with the 3 and 4 factor solutions, in which items load onto both a general factor, and specific sub-factors. In the 4factor solution, the model was not identified. The 3-factor solution converged and produced an excellent fit to the data. Lastly, a second-order CFA was run on the 3-factor solution in which items were indicators of anhedonia sub-factors, and these sub-factors were indicators of an overall factor. The second-order model produced a good fit to the data [see Table 3]. Both analyses indicate that when using the 3 -factor solution, the ASA can be used as measure of one underlying construct, as well as, as a multidimensional measure. 
Table 3. Fit indices for the 14-item Anhedonia Scale for Adolescents (ASA) Factor Solutions

\begin{tabular}{|c|c|c|c|c|c|c|c|c|}
\hline Model & Description & $\begin{array}{l}\text { Type of } \\
\text { Factor } \\
\text { Analysis }\end{array}$ & Sample & Robust $X^{2} / \mathrm{Df}$ & $\begin{array}{l}\text { RMSEA with } \\
90 \%[C I]\end{array}$ & SRMR & CFI & TLI \\
\hline 1 & 1 Factor & EFA & A & - & $.10[.09, .11]$ & - & - & .90 \\
\hline 2 & 2 Factors & EFA & A & - & $.09[.08, .09]$ & - & - & .92 \\
\hline 3 & 3 Factors & EFA & A & - & $.07[06, .08]$ & & - & .95 \\
\hline 4 & 4 Factors & EFA & A & - & $.05[.05, .0$ & & - & .97 \\
\hline 5 & $\begin{array}{l}2 \text { Factors } \\
\text { [negatively framed] }\end{array}$ & CFA & A & $491 / 76=6.5$ & & & .97 & .97 \\
\hline 6 & $\begin{array}{l}3 \text { Factors } \\
\text { [negatively framed] }\end{array}$ & CFA & A & $352 / 74=4.8$ & & .03 & .98 & .98 \\
\hline 7 & $\begin{array}{l}4 \text { Factor } \\
\text { [negatively framed] }\end{array}$ & CFA & A & $309 / 71$ & $.05, .07]$ & .03 & .99 & .98 \\
\hline 8 & 1 Factor & CFA & B & & $.09[.08, .09]$ & .05 & .96 & .95 \\
\hline 9 & 2 Factors & CFA & B & $411 / 76$ & $.07[.06, .07]$ & .04 & .98 & .97 \\
\hline 10 & 3 Factors & CFA & & $300 / 74=4.1$ & $.05[.05, .06]$ & .04 & .98 & .98 \\
\hline 11 & 4 Factors & CFA & & $258 / / 71=3.6$ & $.05[.04, .06]$ & .03 & .99 & .98 \\
\hline 12 & $\begin{array}{l}\text { Bifactor Model [1 } \\
\text { general factor, } 3 \\
\text { specific factors] }\end{array}$ & & & $208 / 63=3.3$ & $.05[.04, .05]$ & .03 & .99 & .99 \\
\hline 13 & $\begin{array}{l}\text { Second-Order Model } \\
{\left[1^{\text {st }} \text { overall factor, } 3\right.} \\
\text { specific factors }]\end{array}$ & CFA & B & $314 / 76=4.1$ & $.06[.05, .06]$ & .04 & .98 & .98 \\
\hline
\end{tabular}

Note EFA = exploratory factor analysis [principal axis factoring]; $\mathrm{CFA}=$ confirmatory factor analysis [WLSMV]; Df = degrees of freedom; RMSEA = root mean square error of approximation; $\mathrm{CI}=$ confidence intervals; SRMR = standardised root mean square residual; $\mathrm{CFI}=$ comparative fit index; TLI $=$ tucker lewis index. 


\section{Internal Consistency and Test-Retest Reliability}

Internal consistency reliability. The total 14-item scale and its individual factors were internally consistent based on ordinal Cronbach alpha $(\alpha)$ and omega $(\omega)$ reliability statistics (see Tables 1 and 2).

Test re-test reliability. A sub-sample of participants $(\mathrm{n}=200)$ completed the ASA and MFQ at a convenience opportunity of 7-11 weeks after the first completion. This sub-sample significantly differed from the main pool of participants with more males (original sample, $56 \%$ female; retest sample, $33 \%$ female; $\left.X^{2}(1)=35.510, p<.05\right)$, younger participants (original sample age $\mathrm{M}=14.38, \mathrm{SD}=2.08$; retest sample age $\mathrm{M}=13.93, \mathrm{SD}=1.68 ; \mathrm{t}(268)=$ $3.524, \mathrm{p}<.05$ ) and more participants identifying as White British (original sample, 50\% White British; retest sample, $58 \%$ White British, $\left(X^{2}(1)=3.989, p=.046\right)$. Participants who completed fewer than $75 \%$ of the scale items were removed from the analysis $(n=10)$. The 14-item adolescent anhedonia scale demonstrated high temporal reliability for the total scale $(\mathrm{ICC}=.73[.634, .794], \mathrm{p}<.001)$ and each sub-scale $(\mathrm{F} 1.78 ; \mathrm{F} 2.77 ; \mathrm{F} 3.74 ; \mathrm{p}<.001)$ Furthermore, the total ASA at re-test had moderate to high temporal reliability with depression at re-test (MFQ) (ICC .640 [.521, .729], p<.001).

\section{Descriptive Statistics by Age and Gender}

For the 14-item ASA, mean total and sub-scale scores were significantly higher for female $(M=13.2, S D=7.7)$ than male $(M=10.3, S D=6.6)$ participants, $t(2060)=9.01, p$ $<.001$. Scores were also significantly higher in older (ages $15-18, \mathrm{M}=12.94, \mathrm{SD}=7.52$ ) compared to younger (ages $11-14, \mathrm{M}=10.44, \mathrm{SD}=6.87$ ) participants, $\mathrm{t}(1861)=-7.81$, $\mathrm{p}<.001$. See Supplementary Material D for further details.

\section{Convergent and Discriminant Validity}

Correlational analysis. In order to test convergent and discriminant validity we examined correlations between the ASA total scale and sub-scales and other measures of 
anhedonia and related constructs (depression, negative symptoms, positive and negative affect, behavioural approach and inhibition, and anxiety). Participants who completed at least $75 \%$ of items were included in the analyses (see tables 3 and 4 for number of participants per analysis). The ASA correlated strongly (.6 - .7) with depression (MFQ); positive and negative affect (PANAS) and negative symptoms of schizophrenia (SNS), moderately (.4 - .6) with other measures of pleasure (SHAPS, ACIPS) and anxiety (RCADS), and had weak correlations with personality traits of behavioural approach and inhibition (.1-.4). 
Table 4. Correlations between the Anhedonia Scale for Adolescents (ASA) with 3 subscales and other related measures (Sample A)

\begin{tabular}{|c|c|c|c|c|c|c|c|c|c|c|c|c|c|}
\hline & ASA & ASA-F1 & ASA-F2 & ASA-F3 & MFQ & SHAPS & $\begin{array}{l}\text { BAS- } \\
\text { REWARD }\end{array}$ & $\begin{array}{l}\text { BAS- } \\
\text { DRIVE }\end{array}$ & & BIS & $\begin{array}{l}\text { PANAS- } \\
\text { PA }\end{array}$ & $\begin{array}{l}\text { PANAS- } \\
\text { NA }\end{array}$ & $\begin{array}{l}\text { RCADS- } \\
\text { OCD }\end{array}$ \\
\hline$\overline{\text { ASA }}$ & - & & & & & & & & & & & & \\
\hline ASA- F1 & $.899 * *$ & - & & & & & & & & & & & \\
\hline ASA- F2 & $.786 * *$ & $.569 * *$ & - & & & & & & & & & & \\
\hline ASA- F3 & $.867 * *$ & $.692 * *$ & $.545^{* *}$ & - & & & & & & & & & \\
\hline MFQ & $.785 * *$ & $.781 * *$ & $.553 * *$ & $.673 * *$ & - & & & & & & & & \\
\hline SHAPS & $.499 * *$ & $.420 * *$ & $.508 * *$ & $.390 * *$ & $.350 * *$ & - & & & & & & & \\
\hline BAS- & $.319 * *$ & $.247 * *$ & $.380 * *$ & $.231 * *$ & $.170 * *$ & . & & & & & & & \\
\hline REWARD & & & & & & & & & & & & & \\
\hline BAS-DRIVE & $.131 * *$ & .046 & $.201 * *$ & $.116^{* *}$ & .050 & $.190 * *$ & $.396 * *$ & - & & & & & \\
\hline BAS-FUN & $.188 * *$ & $.140 * *$ & $.220 * *$ & $.148 * *$ & $.113 * *$ & 0 & $.452 * *$ & $.261 * *$ & - & & & & \\
\hline BIS & $-.403 * *$ & $-.414 * *$ & $-.249 * *$ & $-.362 * *$ & $-525 * *$ & & $.102 * *$ & .016 & $-.084 * *$ & - & & & \\
\hline PANAS-PA & $-.673 * *$ & $-.592 * *$ & $-.634 * *$ & $-.533 * *$ & $-.615 * *$ & $-.491 * *$ & $-.397 * *$ & $-.185 * *$ & $-.263 * *$ & $.340 * *$ & - & & \\
\hline PANAS-NA & $.637 * *$ & $.633^{* *}$ & $.480 * *$ & $.511 * *$ & $.756 * *$ & $.301 * *$ & $.113 * *$ & .032 & $.104 * *$ & $-.507 * *$ & $-.497 * *$ & - & \\
\hline RCADS-OCD & $.519 * *$ & $.536 * *$ & $.320 * *$ & $.443 * *$ & $.624 * *$ & $.171 * *$ & .058 & -.023 & .045 & $-.472 * *$ & $-.307 * *$ & $.536 * *$ & - \\
\hline N (Per Scale) & 1055 & 1055 & 1032 & 1056 & 1002 & 1008 & 1001 & 800 & 1001 & 959 & 996 & 995 & 1010 \\
\hline
\end{tabular}

Note. Spearman's Rho correlations are significant $* *=p<.001, *=p<.05$. ASA $=$ Anhedonia Scale for Adolescents; ASA F1 = Adolescent Anhedonia Subscale 1; ASA F2 = Adolescent Anhedonia Subscale 2; ASA F3 = Adolescent Anhedonia Subscale 3; MFQ = Mood and Feelings Questionnaire; SHAPS = Snaith Hamilton Pleasure Scale; BAS = Behavioural Approach Subscales; BIS = Behavioural Inhibition Subscale; PANAS = Positive and Negative Affect Scale; RCADS-OCD = Revised Child Anxiety and Depression Scale - Obsessive Compulsive Disorder. 
Table 5. Correlations between the Anhedonia Scale for Adolescents (ASA) with 3 subscales and other related measures (Sample B)

\section{ASA \\ ASA-F1 ASA-F2 ASA-F 3 MFQ \\ ACIPS-A \\ SNS- TOTAL APATHY EMOTIONAL \\ RCADS-P RCADS-G} (1)

\begin{tabular}{|c|c|c|c|c|c|c|c|c|c|}
\hline$\overline{\text { ASA }}$ & - & & & & & & & & \\
\hline ASA- F1 & $.891 * *$ & - & & & & & & & \\
\hline ASA- F2 & $.803 * *$ & $.588 * *$ & - & & & & & & \\
\hline ASA- F3 & $.843 * *$ & $.656 * *$ & $.529 * *$ & - & & & & & \\
\hline ACIPS-A & $-.484 * *$ & $-.438 * *$ & $-.474 * *$ & $-.353 * *$ & $-.361 * *$ & - & & & \\
\hline SNS-TOTAL & $706 * *$ & $.678 * *$ & $.525^{* *}$ & $.603 * *$ & $.741 * *$ & $-.492 * *$ & & & \\
\hline SNS- APATHY & $.725 * *$ & $.684 * *$ & $.548^{* *}$ & $.624 * *$ & $.759 * *$ & $-.490 * *$ & & & \\
\hline RCADS-P & $.480 * *$ & $.473 * *$ & $.328 * *$ & $.424 * *$ & $.639 * *$ & $.518 * * \quad .524 * *$ & $.311 * *$ & - & \\
\hline RCADS-G & $.494 * *$ & $.492 * *$ & $.347 * *$ & $.411 * *$ & $.627 * *$ & $-.187 * * \quad .530 * *$ & $.275^{* *}$ & $.631 * *$ & - \\
\hline N (Per Scale) & 1040 & 1039 & 1006 & 1041 & 987 & 971 & 977 & 989 & 983 \\
\hline
\end{tabular}

Note. Spearman's Rho correlations are significant $* *=\mathrm{p}<.001, *=\mathrm{p}<.05$. ASA $=$ Anhedonia Scale for Adolescents; ASA F1 = Adolescent Anhedonia Subscale 1; ASA F2 = Adolescent Anhedonia Subscale 2; ASA F3 = Adolescent Anhedonia Subscale 3; MFQ = Mood and Feelings Questionnaire; ACIPS-A = Anticipatory and Consummatory Interpersonal Pleasure Scale - Adolescents; SNS = Self-Report Negative Symptoms of Schizophrenia; SNS- APATHY = Self-Report Negative Symptoms of Schizophrenia Apathy (social withdrawal, alogia, avolition and anhedonia), SNS-EMOTIONAL = Self-Report Negative Symptoms of Schizophrenia Emotional (diminished emotional range), RCADS-P = Panic Subscale, RCADS-GAD = Generalised Anxiety Subscale.

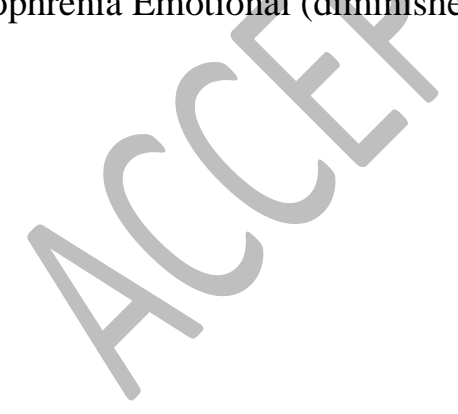


Comparison of correlations. To test if the association between ASA and self-report scales was significantly stronger for convergent versus discriminant measures, comparisons were made between pairs of correlation coefficients from dependent samples. First, it was predicted that the ASA would be more strongly correlated with self-report symptom measures of affective disorders in which anhedonia is a direct feature (depression, MFQ; and negative symptoms of schizophrenia, SNS) than other related disorders (anxiety, RCADS). Correlations below are reported in absolute strength. In Sample A, the strength of the correlation coefficient between the ASA and MFQ $\left(\mathrm{r}_{\mathrm{s} .}\right.$.785) was stronger than between the

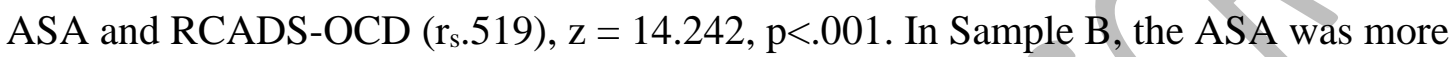
strongly correlated with the MFQ ( $\mathrm{r}_{\mathrm{s} .}$.777) than with the RCADS-PANIC $\left(\mathrm{r}_{\mathrm{s} .} .480\right), \mathrm{z}=15.569$, $\mathrm{p}<.001$, or the RCADS-GAD $\left(\mathrm{r}_{\mathrm{s}} .494\right), \mathrm{z}=14.649, \mathrm{p}<.001$. Furthermore, the association between the ASA and MFQ was stronger ( $\mathrm{r}_{\mathrm{s} .777)}$ than the relationship between the ASA and SNS ( $\left.\mathrm{r}_{\mathrm{s}} .706\right), \mathrm{z}=4.956, \mathrm{p}<.001$, in line with the fact that the ASA was developed in the context of adolescent depression.

Second, it was predicted that the ASA would correlate more strongly with measures of trait or personality like measures of low positive affect (i.e. PA, Ebesutani et al., 2012) and reduced reward processing (i.e. pleasure, SHAPS, Snaith et al., 1995, ACIPS, Gooding et al., 2016; and reward responsiveness, BAS-reward; Carver \& White, 1994; Franken et al., 2005), than with measures of trait/personality measures of high negative affect (NA; Ebesutani et al., 2012), high punishment sensitivity (i.e. BIS; Carver \& White, 1994) and low impulsiverelated approach (i.e. BAS-fun seeking, Franken et al., 2005). Correlations below are reported in absolute strength. In line with predictions, the ASA was more strongly related to low positive affect $(\mathrm{PA})\left(\mathrm{r}_{\mathrm{s}}=.673\right)$ than high negative affect $(\mathrm{NA})\left(\mathrm{r}_{\mathrm{s}}=.637\right), \mathrm{z}=1.661, \mathrm{p}=.048$, but not at the $\mathrm{p}<.001$ significance level. The ASA was more strongly correlated with low reward-responsiveness, BAS-reward $\left(\mathrm{r}_{\mathrm{s}}=.319\right)$, than with low BAS-fun seeking $\left(\mathrm{r}_{\mathrm{s}}=.188\right), \mathrm{z}$ 
$=4.125, \mathrm{p}<.001$, but not with high behavioural inhibition (BIS), $\left(\mathrm{r}_{\mathrm{s}}=.403\right), \mathrm{z}=-2.152$, $\mathrm{p}=.016$. As anticipated, the ASA correlated more strongly with low levels of pleasure (SHAPS) $\left(\mathrm{r}_{\mathrm{s}}=.499\right)$ than with high behavioural inhibition (BIS) $\left(\mathrm{r}_{\mathrm{s}}=.403\right), \mathrm{z}=2.527, \mathrm{p}=.006$, or low levels of impulsive-related approach (BAS-fun seeking $\left.\left(\mathrm{r}_{\mathrm{s}}=.188\right), \mathrm{z}=9.159, \mathrm{p}<.001\right)$. An independent samples comparison (ACIPS, Sample B; BISBAS Sample A) also found that the ASA correlated more strongly with low anticipatory and consummatory social pleasure (ACIPS-A) $\left(\mathrm{r}_{\mathrm{s}}=.484\right)$ than with low impulsive-related approach $\left(\mathrm{BAS}-\mathrm{fun}\right.$ seeking $\left(\mathrm{r}_{\mathrm{s}}=.188\right)$, $\mathrm{z}=7.510, \mathrm{p}<.001$, or high behavioural inhibition $\left(\mathrm{BIS}\left(\mathrm{r}_{\mathrm{s}}=.403\right), \mathrm{z}=2.219, \mathrm{p}=.013\right.$.

Hierarchical linear regression. In order to further understand ASA' nomological network, multiple hierarchical step-wise linear regressions were run to examine how much variance of the ASA was explained by related constructs (convergent measures). Correlations were entered into the model in accordance with the strength of the correlation coefficient (highest to lowest). For Sample A, ASA scores were significantly predicted by depression (MFQ), explaining $65 \%$ of the variance $\left(R^{2}=.65\right)$, positive affect (PANAS-PA), explaining a further $6 \%$ of the variance $\left(\Delta R^{2}=.06\right)$, pleasure (SHAPS) explaining a further $3 \%\left(\Delta R^{2}=.03\right)$, and reward responsiveness (BAS-reward), explaining an additional $<1 \%$ of the variance $\left(\Delta R^{2}\right.$ $=.003$ ). A total of $74 \%$ of the variance was accounted for by the convergent measures, $F(4,945)=673.74, p<.001$. For Sample B, ASA scores were significantly predicted by depression (MFQ) explaining $64 \%$ of the variance $\left(R^{2}=.64\right)$, negative symptoms of schizophrenia (SNS), explaining a further $4 \%\left(\Delta R^{2}=.04\right)$, and measures of pleasure (ACIPS), explaining a further $2 \%$ of the variance $\left(\Delta R^{2}=.02\right)$. A total of $71 \%$ of the variance was accounted for by convergent measures, $F(3,932)=741.80, \mathrm{p}<.001$. See Table 6 .

\section{Incremental and Predictive Validity}

Hierarchical logistic regression. In Sample A, SHAPS responses significantly predicted membership of the depressed group (high vs. low MFQ scores), explaining $21 \%$ of 
the variance, Nagelkerke $R^{2}=.21, \mathrm{X}^{2}(1)=150.58, \mathrm{p}<.001$. When ASA responses were subsequently entered into the model there was a significant increase in the prediction of clinical group, Nagelkerke $R^{2}=.62, \mathrm{X}^{2}(2)=541.59, \mathrm{p}<.001$, but the SHAPS was no longer a significant predictor $(\mathrm{p}=.480)$. In Sample $\mathrm{B}$, ACIPS-A responses significantly predicted MFQ status, Nagelkerke $R^{2}=.16, \mathrm{X}^{2}(1)=105.93, \mathrm{p}<.001$. When ASA responses were subsequently entered into the model, there was a significant increase in the prediction of MFQ clinical status, Nagelkerke $R^{2}=.60, \mathrm{X}^{2}(2)=452.30, \mathrm{p}<.001$, but again the ACIPS was no longer a significant predictor $(\mathrm{p}=.745)$ of clinical group. See Table 6.

Simple logistic regression. To assess the predictive validity of the ASA simple linear regression was used to establish if ASA scores at time point 1 in the re-test subsample $(\mathrm{n}=$ 200) was a significant predictor of depressive status (high or low MFQ scores) at time point 2 (range $=7-11$ weeks). The ASA scores significantly predicted depressive status, Nagelkerke $R^{2}=.31, \mathrm{X}^{2}(1)=42.06, \mathrm{p}<.001$. 
Table 6. Regression analyses to test for the convergent and incremental validity of ASA scores

Hierarchical multiple linear regression (predicting ASA total score from convergent measures)

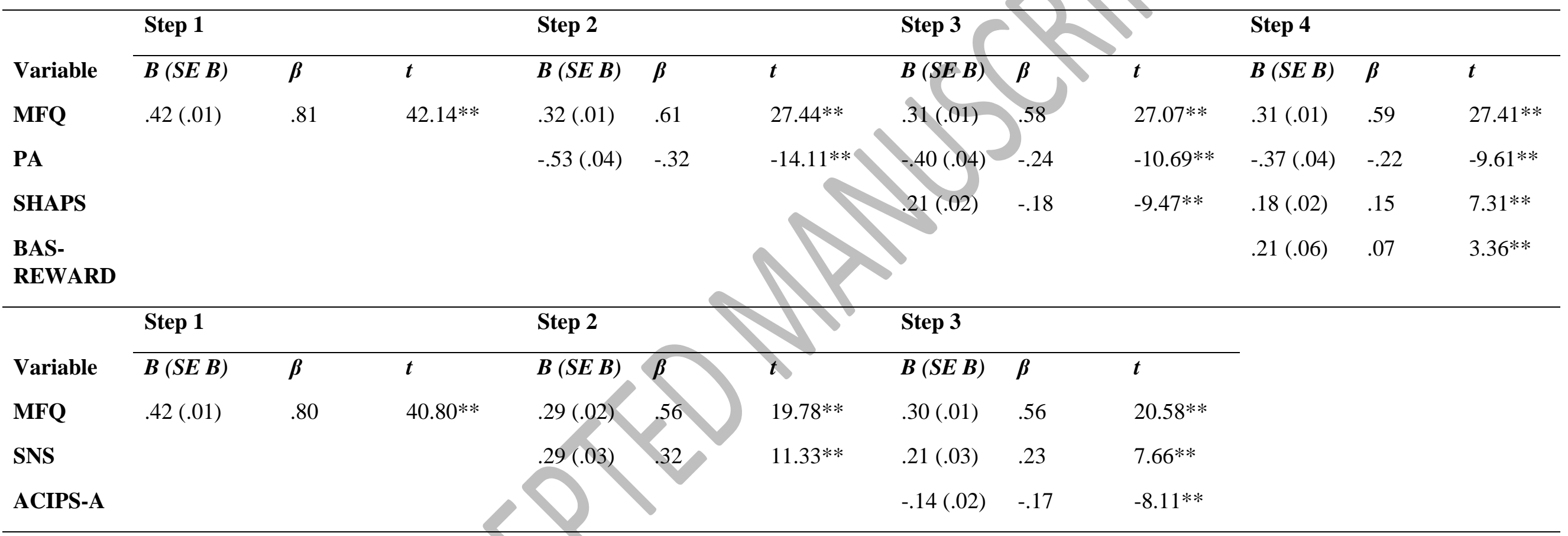

Hierarchical multiple logistic regression (predicting depressive status from measures of anhedonia)

\begin{tabular}{lllllll}
\hline & Step 1 & \multicolumn{5}{c}{ Step 2 } \\
Variable & $B(S E B)$ & Wald $X^{2}$ & OR $[95 \%$ & $B(S E B)$ & Wald $X^{2}$ & OR $[95 \%$ \\
& & & $C I]$ & & $C I]$
\end{tabular}




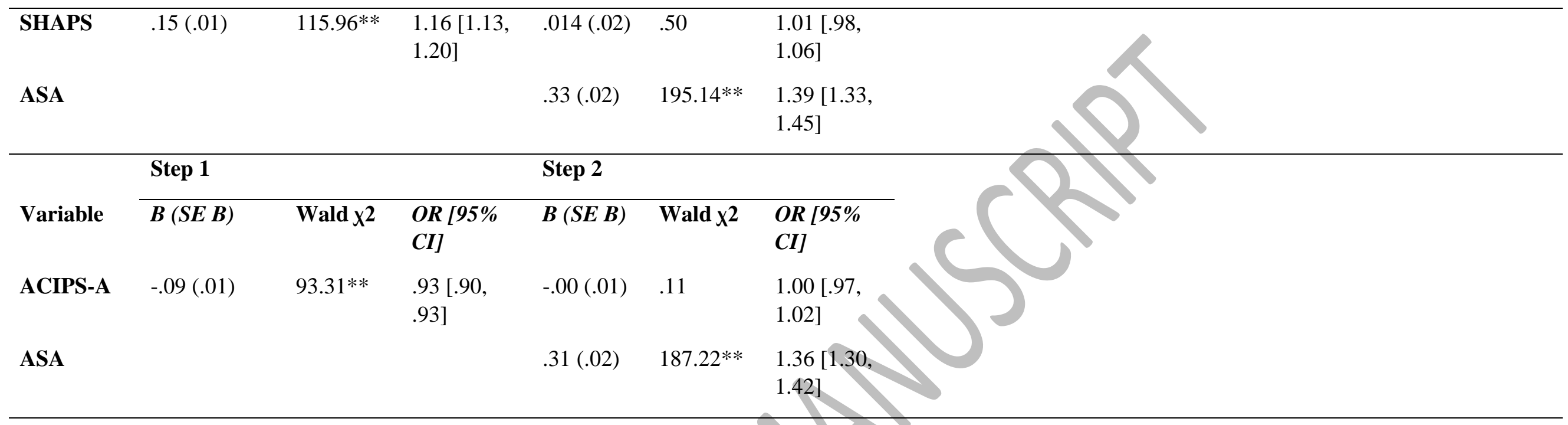

Simple logistic regression (predicting depressive status at time point 2 from ASA scores at time point 1)

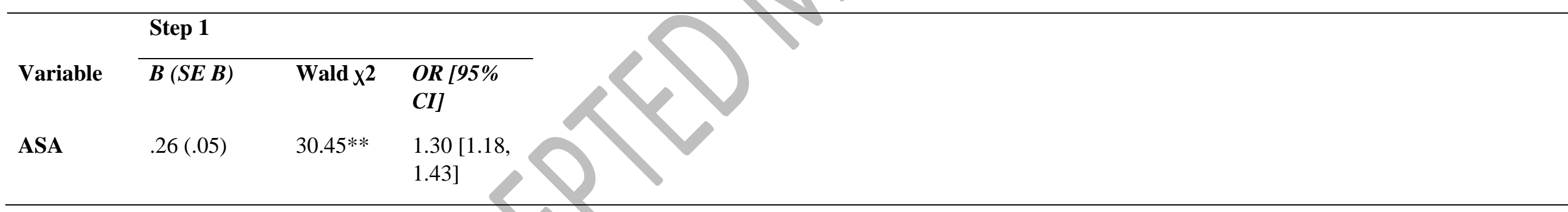

Note. $* \mathrm{p}<.05, * * \mathrm{p}<.001 . B=$ Unstandardized beta, $S E B=$ standard error for unstandardized beta, $\beta=$ Standardized beta, $t=\mathrm{t}$ test statistic, Wald $\mathrm{X}^{2}=\mathrm{Wald}$ chi squared statistic, $\mathrm{OR}=$ Odds ratio, $95 \% \mathrm{CI}=95 \%$ confidence intervals. ASA $=$ Anhedonia Scale for Adolescents, $\mathrm{MFQ}=\mathrm{Mood}$ and Feelings

Questionnaire, PA = Positive Affect Subscale, SHAPS = Snaith Hamilton Pleasure Scale, ACIPS-A = Anticipatory and Consummatory Interpersonal Pleasure

Scale Adolescent Version, BAS REWARD = Behavioural Activation Reward Responsiveness Subscale, SNS = Self-Evaluation of Negative Symptoms. 


\section{Discussion}

The aim of this study was to develop an adolescent specific measure of anhedonia and to provide initial validation data. The initial pool of items was elicited from qualitative interviews with adolescents, piloted and then tested in two sub-samples to assess clarity, meaning, face validity, acceptability and coherence. The scale was explored and then confirmed using factor analysis, resulting in a 14-item scale. The best fit to the data was a bifactor solution, in which items loaded onto a general factor and 3 theoretically salient specific factors: 1) Enjoyment, Excitement and Emotional Flattening (negatively framed); 2) Enthusiasm, Meaning and Purpose (positively framed); 3) Effort, Motivation and Drive (negatively framed). Other psychometric properties of the ASA were acceptable, with high internal consistency, high test re-test reliability, and stronger convergence with measures of depression, anhedonia and negative symptoms of schizophrenia, than measures of anxiety, negative affect, behavioural inhibition and approach-related impulsivity.

In contrast to previous scales that have been developed for adults (DARS, Rizvi et al., 2015) and adapted for adolescents (ACIPS, Gooding et al., 2016), ASA items loaded onto separate factors that disambiguated some anticipatory/motivational elements from more consummatory aspects of anhedonia. The first factor relates to affective aspects of anhedonia, including the absence of the experience of enjoyment, excitement and a sense of emotional flattening and detachment. The second factor reflects the experience of connection, purpose and enthusiasm. The third factor captures a lack of drive, effort and motivation. These separate subscales reflect young people's complex and nuanced experiences of anhedonia and therefore may capture subtle distinctions that are heightened during adolescence. Unlike most anhedonia scales the ASA measures a broad range of deficits in the anticipation, motivation and enjoyment of rewards and the experience of feeling a sense of connection and purpose (Watson et al., 2020). Previous scales have predominantly focused on loss of 
enjoyment/consummatory pleasure (e.g. the SHAPS; Snaith et al., 1995) and very few have considered self-reported effort as a measure of motivation for reward (McCabe, 2018). This is important because there is recent evidence that motivation, measured by the physical effort to attain reward, is a key component of anhedonia in adolescents (Rzepa et al., 2017; Rzepa \& McCabe, 2019). Thus, self-reported motivation and the physical effort to attain rewards is an aspect of anhedonia in adolescents that is under examined and requires further investigation.

The teenage years are associated with heightened reward seeking (e.g. Shulman et al., 2016) but also high levels of boredom and apathy (e.g. Spaeth et al., 2015), which can make it difficult to distinguish normal teenage development from problematic levels of anhedonia or reward-related symptomology. When measured cross sectionally, the number of adolescents with anhedonia was higher in older adolescents. This trend was observed in both males and females, and similar to self-reported measures of depression symptoms, adolescents' anhedonia scores were higher in females than males. Overall, older adolescents reported higher levels of demotivation than emotional flattening on the ASA, particularly in males, and ASA scores correlated strongly with the apathy subscale of the Self-Report Negative Symptom Scale (SNS). However, future research is needed to conduct an assessment of measurement invariance of ASA scores across age and gender to understand potential group differences; and importantly, longitudinal studies are needed to establish within person changes in ASA scores across adolescence. It will also be of interest to assess if the subscales of the ASA are associated with behavioural measures of physical effort in young people with depression and with the neural response to anticipation, effort and consumption.

Similarly, concepts such as loss of purpose and connection are typically not captured by measures of anhedonia, despite being central to adolescents' subjective experience of 
losing interest and pleasure (Watson et al., 2020), and these concepts are recognised as an important part of the assessment of hedonic well-being and functioning (Keyes, 2005). Losing a sense of connection and purpose may be particularly important during adolescence, as this is a critical time for relationship and identity formation (Christie \& Viner, 2005; Mills et al., 2014). Furthermore, in line with adolescents' qualitative experiences, a sense of social detachment or masking (i.e. I pretended things were fun, but actually I found them boring) is captured in the ASA. Previous research has found a strong relationship between social anhedonia and social closeness in adults (Olino et al., 2016). This loss may be particularly felt during adolescence, as it is typically a time of enhanced sensitivity to social rewards and peer influence (e.g. O’Brien et al., 2011).

As hypothesised ASA had a large positive correlation with a well-established measure of adolescent depression and a medium to large positive correlation with aspects of the negative symptoms of schizophrenia measure, but importantly it retained some unique variance. Scores on ASA were also significantly positively correlated with self-report ratings of anxiety, but these correlations were significantly weaker than correlations between the ASA and measures of depression and negative symptoms of schizophrenia. Some overlap between these constructs is inevitable because of the well-established co-morbidity between depression and anxiety disorders (e.g. Brady \& Kendall, 1992) as well as shared method variance (Reio, 2010). Furthermore, Clark \& Watson, (2019) identified that the inclusion of negatively valenced mood items may result in capturing some aspect of negative affectivity or neuroticism. Therefore, an important next step for the validation of the ASA is to examine how it performs in a clinical sample chosen for diagnostic and symptom specificity, i.e. where the presence or absence of anxiety disorders and depression with and without anhedonia has been confirmed by clinical interview. 
There were also moderate correlations between the ASA and existing measures of pleasure (the SHAPS and ACIPS) that are used to assess anhedonia. The strength of these relationships may have been attenuated because of the narrow focus of the SHAPS on consummatory pleasure SHAPS, Snaith et al., 1995 and the ACIPS on response to social rewards (ACIPS, Gard et al., 2006). Importantly, the ASA significantly predicted elevated depression symptoms (high vs. low MFQ scores) above and beyond other measures of anhedonia/pleasure (ACIPS, Gooding et al., 2014; SHAPS, Leventhal et al., 2015; TEPS, Gard et al., 2006). Furthermore, the ACIPS and SHAPS no longer predicted depressive status once the ASA was entered into the model, highlighting the clinical potential of the ASA.

As expected, the ASA was more strongly correlated with the Behavioural Approach System (BAS) reward responsiveness scale than BAS drive and fun seeking, as high BAS reward responsiveness has been identified as a unique predictor of wellbeing and affect regulation and low levels of internalising disorders, in comparison to other scales in the BIS/BAS (Taubitz et al, 2015). Furthermore, correlations with the BAS drive and fun seeking scales were small, demonstrating some discriminant validity, as these subscales have been linked to functional and dysfunctional impulsive-related approach behaviours, respectively (e.g. Franken et al, 2005), which arguably differs from the construct of anhedonia. Although the ASA was not more strongly related to low reward responsiveness (BAS-reward) than high behavioural inhibition (BIS), this may relate to the link between behavioural inhibition and neuroticism (e.g. Smits \& Boeck, 2006), a personality feature that is closely related to internalising disorders such as depression (APA, 2013).

Importantly, although anhedonia is typically conceptualised as changes in the positive valence system which includes multiple components of reward processing (Research Domain Criteria, RDoC; Insel et al., 2010); it is also conceptualised within the RDoC negative valence system domain subsystem of 'loss' which involves a state of motivation 
deprivation (NIMH, 2011b) that might be tapped into by questions negative affect or behavioural inhibition. This highlights the complex nature of anhedonia, and identifies the need for ongoing investigation into the mechanisms of change (e.g. Khazanov et al., 2020; Khazanov \& Ruscio, 2016) and for consideration as to where this clinical construct should sit within the positive and negative valence system domains of interest.

This study had a number of strengths including robust construct validity. Items were generated from qualitative interviews with young people, which ensured that the constructs assessed align with adolescents' experiences and that the language and content are familiar and understood by this age group. The qualitative interviews also highlighted more diverse aspects of adolescents' experiences of anhedonia, including reduced motivation and effort, and reduced connection and purpose that are not typically assessed as part of anhedonia. Extensive feedback was collected from a large and ethnically diverse sample of adolescents spanning the developmental period (i.e. ages 11 to 18 years). This feedback also helped to ensure that the final scale was acceptable for the target population, but additional work is needed to validate the 14-items of the ASA as a stand-alone scale. Furthermore, some adolescents suggested they would have preferred a 5-point Likert scale, therefore further validation studies could consider including an option between never and sometimes i.e. rarely/occasionally. The descriptions of anhedonia captured in the original qualitative study which formed the basis for the ASA were often broad and all compassing, for example adolescents often found everything boring or nothing fun, rather than not enjoying some things or certain specific activities (Watson et al., 2020). Scale development and validation should be an iterative process and it will be important for future studies to continue to gather feedback from adolescents with depression to ensure their experiences are captured by the new scale and if/where necessary to make any further adaptations. Limitations to the study included moderate assessment of discriminant validity. Further studies are needed to confirm 
if the ASA is able to discriminate between anhedonia and other unrelated disorders and to discriminate between young people who have depression with and without comorbid anxiety. The next step is to assess the performance of the ASA in well-defined clinical samples. This would also help to determine the optimal cut-off score for identifying problematic levels of anhedonia, which would be useful for community screening and clinical assessment.

Likewise, including the ASA in treatment studies, i.e. as a baseline and outcome measure, would help establish if the measure is sensitive to changes in the severity of anhedonia.

In summary the ASA is the only measure of anhedonia that has been designed specifically with and for use by adolescents. It is based directly upon the experiences of anhedonia in adolescents with depression. It has good psychometric properties and will help clinicians and researchers to assess the multiple dimensions of anhedonia that adolescents experience. Subject to further clinical evaluation this new measure has the potential to fill a gap in the assessment tools available to researchers and clinicians who want to understand and treat adolescents experiencing the disabling symptom of anhedonia. 


\section{References}

Angold, A., Costello, E. J., \& Pickles, A. (1987). The development of a questionnaire for use in epidemiological studies of depression in children and adolescents. Medical Research Council Child Psychiatry Unit.

APA. (2013). Diagnostic and Statistical Manual of Mental Disorder (5th Ed.). American Psychiatric Association.

Auerbach, R. P., Pisoni, A., Bondy, E., Kumar, P., Stewart, J. G., Yendiki, A., \& Pizzagalli, D. A. (2017). Neuroanatomical prediction of anhedonia in adolescents. Neuropsychopharmacology, 42(10), 2087-2095. https://doi.org/10.1038/npp.2017.28

Berridge, K. C. (2003). Pleasures of the brain. In Brain and Cognition (Vol. 52, Issue 1, pp. 106-128). Academic Press Inc. https://doi.org/10.1016/S0278-2626(03)00014-9

Berridge, K. C., \& Kringelbach, M. L. (2008). Affective neuroscience of pleasure: Reward in humans and animals. Psychopharmacology, 199(3), 457-480. https://doi.org/10.1007/s00213-008-10996

Berridge, K. C., \& Kringelbach, M. L. (2015). Pleasure Systems in the Brain. Neuron, 86(3), 646664. https://doi.org/10.1016/j.neuron.2015.02.018

Boateng, G. O., Neilands, T. B., Frongillo, E. A., Melgar-Quiñonez, H. R., \& Young, S. L. (2018). Best Practices for Developing and Validating Scales for Health, Social, and Behavioral Research: A Primer. Frontiers in Public Health, 6, 149.

https://doi.org/10.3389/fpubh.2018.00149

Braun, V., \& Clarke, V. (2006). Using thematic analysis in psychology. Qualitative Research in Psychology, 3(2), 77-101. https://doi.org/10.1191/1478088706qp063oa

Burleson Daviss, W., Birmaher, B., Melhem, N. A., Axelson, D. A., Michaels, S. M., \& Brent, D. A. (2006). Criterion validity of the Mood and Feelings Questionnaire for depressive episodes in clinic and non-clinic subjects. Journal of Child Psychology and Psychiatry and Allied Disciplines, 47(9), 927-934. https://doi.org/10.1111/j.1469-7610.2006.01646.x 
Brady, E. U., \& Kendall, P. C. (1992). Comorbidity of anxiety and depression in children and adolescents. Psychological bulletin, 111(2), 244.

Carver, C. S., \& White, T. L. (1994). Behavioral Inhibition, Behavioral Activation, and Affective Responses to Impending Reward and Punishment: The BIS/BAS Scales. Journal of Personality and Social Psychology, 67(2), 319-333. https://doi.org/10.1037/0022-3514.67.2.319

Casey, B. J., Jones, R. M., \& Somerville, L. H. (2011). Braking and accelerating of the adolescent brain. Journal of Research on Adolescence, 21(1), 21-33. https://doi.org/10.1111/j.15327795.2010.00712.x

Chapman, L. J., Chapman, J. P., \& Raulin, M. L. (1976). Scales for physical and social anhedonia. Journal of Abnormal Psychology, 85(4), 374-382. https://doi.org/10.1037/0021-843X.85.4.374

Christie, D., \& Viner, R. (2005). Adolescent development. BMJ, 330(7486), 301. https://doi.org/10.1136/bmj.330.7486.301

Chorpita, B. F., Yim, L., Moffitt, C., Umemoto, L. A., \& Francis, S. E. (2000). Assessment of symptoms of DSM-IV anxiety and depression in children: A revised child anxiety and depression scale. Behaviour research and therapy, 38(8), 835-855.

Clark, L.A., \& Watson, D. (2019). Constructing validity: New developments in creating objective measuring instruments. Psychological Assessment, 31(12), 1412-1427. https://doi.org/10.1037/pas0000626

Clark, Lee Anna, \& Watson, D. (1995). Constructing Validity: Basic Issues in Objective Scale Development. Psychological Assessment, 7(3), 309-319. https://doi.org/10.1037/10403590.7.3.309

Clayborne, Z. M., Varin, M., \& Colman, I. (2019). Systematic Review and Meta-Analysis: Adolescent Depression and Long-Term Psychosocial Outcomes. Journal of the American Academy of Child and Adolescent Psychiatry, 58(1), 72-79. https://doi.org/10.1016/j.jaac.2018.07.896

Craske, M. G., Treanor, M., Dour, H., Meuret, A., \& Ritz, T. (2019). Positive Affect Treatment for Depression and Anxiety: A Randomized Clinical Trial for a Core Feature of Anhedonia. Journal of Consulting and Clinical Psychology, 87(5), 457-471. https://doi.org/10.1037/ccp0000396 
Dollfus, S., Mach, C., \& Morello, R. (2016). Self-Evaluation of Negative Symptoms: A Novel Tool to Assess Negative Symptoms. Schizophrenia Bulletin, 42(3), 571-578.

https://doi.org/10.1093/schbul/sbv161

Dunn, B., Widnall, E., Reed, N., Taylor, R., Owens, C., Spencer, A., Kraag, G., Kok, G., Geschwind, N., Wright, K., Moberly, N. J., Moulds, M. L., MacLeod, A. K., Handley, R., Richards, D., Campbell, J., \& Kuyken, W. (2019). Evaluating Augmented Depression Therapy (ADepT): Study protocol for a pilot randomised controlled trial. Pilot and Feasibility Studies, 5(1), 1-16. https://doi.org/10.1186/s40814-019-0438-1

Dunn, V., \& Goodyer, I. M. (2006). Longitudinal investigation into childhood-and adolescence-onset depression: Psychiatric outcome in early adulthood. British Journal of Psychiatry, 188(MAR.), 216-222. https://doi.org/10.1192/bjp.188.3.216

Ebesutani, C., Regan, J., Smith, A., Reise, S., Higa-McMillan, C., \& Chorpita, B. F. (2012). The 10item Positive and Negative Affect Schedule for Children, Child and parent shortened versions: Application of item response theory for more efficient assessment. Journal of Psychopathology and Behavioral Assessment, 34(2), 191-203. https://doi.org/10.1007/s10862-011-9273-2

Fawcett, J., Clark, D. C., Scheftner, W. A., \& Gibbons, R. D. (1983). Assessing Anhedonia in Psychiatric Patients: The Pleasure Scale. Archives of General Psychiatry, 40(1), 79-84. https://doi.org/10.1001/archpsyc.1983.01790010081010

Fisk, J., Ellis, J. A., \& Reynolds, S. A. (2019). A test of the CaR-FA-X mechanisms and depression in adolescents. Memory, 27(4), 455-464. https://doi.org/10.1080/09658211.2018.1518457

Flora, D. B., \& Flake, J. K. (2017). The Purpose and Practice of Exploratory and Confirmatory Factor Analysis in Psychological Research: Decisions for Scale Development and Validation. https://doi.org/10.1037/cbs0000069

Forbes, E. E., \& Dahl, R. E. (2012). Research Review: Altered reward function in adolescent depression: What, when and how? In Journal of Child Psychology and Psychiatry and Allied Disciplines. https://doi.org/10.1111/j.1469-7610.2011.02477.x

Franken, I. H. A. A., Rassin, E., \& Muris, P. (2007). The assessment of anhedonia in clinical and nonclinical populations: Further validation of the Snaith-Hamilton Pleasure Scale (SHAPS). Journal 
of Affective Disorders, 99(1-3), 83-89. https://doi.org/10.1016/j.jad.2006.08.020

Franken, I. H. A., Muris, P., \& Rassin, E. (2005). Psychometric Properties of the Dutch BIS/BAS Scales. Journal of Psychopathology and Behavioral Assessment, 27(1). https://doi.org/10.1007/s10862-005-3262-2

Galvan, A. (2010). Adolescent development of the reward system. In Frontiers in Human Neuroscience (Vol. 4, p. 6). Frontiers Media S. A. https://doi.org/10.3389/neuro.09.006.2010 Gard, D. E., Gard, M. G., Kring, A. M., \& John, O. P. (2006). Anticipatory and consummatory components of the experience of pleasure: A scale development study. Journal of Research in Personality, 40(6), 1086-1102. https://doi.org/10.1016/j.jrp.2005.11.001

Gooding, D., \& Pflum, M. (2014). The assessment of interpersonal pleasure: Introduction of the Anticipatory and Consummatory Interpersonal Pleasure Scale (ACIPS) and preliminary findings. Psychiatry Research, 215(1), 237-243. https://doi.org/10.1016/j.psychres.2013.10.012 Gooding, D., Pflum, M., Fonseca-Pedero, E., \& Paino, M. (2016). Assessing social anhedonia in adolescence: The ACIPS-A in a community sample. European Psychiatry, 37(August), 49-55. https://doi.org/10.1016/j.eurpsy.2016.05.012

Goodyer, I. M., Reynolds, S., Barrett, B., Byford, S., Dubicka, B., Hill, J., Holland, F., Kelvin, R., Midgley, N., Roberts, C., Senior, R., Target, M., Widmer, B., Wilkinson, P., \& Fonagy, P. (2017). Cognitive behavioural therapy and short-term psychoanalytical psychotherapy versus a brief psychosocial intervention in adolescents with unipolar major depressive disorder (IMPACT): a multicentre, pragmatic, observer-blind, randomised controlled superiori. The Lancet Psychiatry, 4(2), 109-119. https://doi.org/10.1016/S2215-0366(16)30378-9

Gorwood, P. (2008). Neurobiological mechanisms of anhedonia. Dialogues in Clinical Neuroscience, 10(3), 291-299.

GOV.UK (2020) Find and compare schools in England. https://www.gov.uk/schoolperformance-tables. Accessed 1 March 2020.

Halahakoon, D. C., Kieslich, K., O’Driscoll, C., Nair, A., Lewis, G., \& Roiser, J. P. (2020). RewardProcessing Behavior in Depressed Participants Relative to Healthy Volunteers. JAMA Psychiatry. https://doi.org/10.1001/jamapsychiatry.2020.2139 
Hawton, K., Saunders, K. E. A., \& O’Connor, R. C. (2012). Self-harm and suicide in adolescents. In The Lancet (Vol. 379, Issue 9834, pp. 2373-2382). Lancet Publishing Group. https://doi.org/10.1016/S0140-6736(12)60322-5

Insel, T., Cuthbert, B., Garvey, M., Heinssen, R., Pine, D., Quinn, K., Sanislow, C., \& Wang, P. (2010). Research Domain Criteria ( RDoC ): Toward a. American Journal of Psychiatry Online, July, 748-751. https://doi.org/10.1176/appi.ajp.2010.09091379

Kaya, S., \& McCabe, C. (2019). Can Understanding Reward Help Illuminate Anhedonia? Current Behavioral Neuroscience Reports, 6(4), 236-242. https://doi.org/10.1007/s40473-019-00186-1

Keyes, C. L. M. (2005). Mental illness and/or mental health? Investigating axioms of the complete state model of health. Journal of Consulting and Clinical Psychology, 73(3), 539-548. https://doi.org/10.1037/0022-006X.73.3.539

Khazanov, Gabriela K., Xu, C., Dunn, B. D., Cohen, Z. D., DeRubeis, R. J., \& Hollon, S. D. (2020). Distress and anhedonia as predictors of depression treatment outcome: A secondary analysis of a randomized clinical trial. Behaviour Research and Therapy, 125, 103507. https://doi.org/10.1016/j.brat.2019.103507

Khazanov, Gabriela Kattan, \& Ruscio, A. M. (2016). Is low positive emotionality a specific risk factor for depression? A meta-Analysis of longitudinal studies. Psychological Bulletin, 142(9), 991-1015. https://doi.org/10.1037/bul0000059

Khazanov, Gabriela Kattan, Ruscio, A. M., \& Forbes, C. N. (2020). The Positive Valence Systems Scale: Development and Validation. Assessment, 27(5), 1045-1069. https://doi.org/10.1177/1073191119869836

Kring, A. M., \& Barch, D. M. (2014). The motivation and pleasure dimension of negative symptoms. Eur Neuropsychopharmacol, 24(5), 725-736. https://doi.org/10.1016/j.euroneuro.2013.06.007.The Leventhal, A. M., Unger, J. B., Audrain-McGovern, J., Sussman, S., Volk, H. E., \& Strong, D. R. (2015). Measuring Anhedonia in Adolescents: A Psychometric Analysis. Journal of Personality Assessment, 97(5), 506-514. https://doi.org/10.1080/00223891.2015.1029072

McCabe, C. (2018). Linking anhedonia symptoms with behavioural and neural reward responses in 
adolescent depression. Current Opinion in Behavioral Sciences, 22, 143-151.

https://doi.org/10.1016/j.cobeha.2018.07.001

McMakin, D. L., Olino, T. M., Porta, G., Dietz, L. J., Emslie, G., Clarke, G., Wagner, K. D., Asarnow, J. R., Ryan, N. D., Birmaher, B., Shamseddeen, W., Mayes, T., Kennard, B., Spirito, A., Keller, M., Lynch, F. L., Dickerson, J. F., \& Brent, D. A. (2012). Anhedonia predicts poorer recovery among youth with selective serotonin reuptake inhibitor treatmentresistant depression. Journal of the American Academy of Child and Adolescent Psychiatry, 51(4), 404-411. https://doi.org/10.1016/j.jaac.2012.01.011

Mills, K. L., Lalonde, F., Clasen, L. S., Giedd, J. N., \& Blakemore, S. J. (2014). Developmental changes in the structure of the social brain in late childhood and adolescence. Social Cognitive and Affective Neuroscience, 9(1), 123-131. https://doi.org/10.1093/scan/nss113

Mokkink, L. B., de Vet, H. C. W., Prinsen, C. A. C., Patrick, D. L., Alonso, J., Bouter, L. M., \& Terwee, C. B. (2018). COSMIN Risk of Bias checklist for systematic reviews of PatientReported Outcome Measures. Quality of Life Research, 27(5), 1171-1179. https://doi.org/10.1007/s11136-017-1765-4

Mossman, S. A., Luft, M. J., Schroeder, H. K., Varney, S. T., Fleck, D. E., Barzman, D. H., ... \& Strawn, J. R. (2017). The Generalized Anxiety Disorder 7-item scale in adolescents with generalized anxiety disorder: Signal detection and validation. Annals of clinical psychiatry: official journal of the American Academy of Clinical Psychiatrists, 29(4), 227-234A.

NIMH. (2011a). Negative valence systems: Workshop proceedings. https://www.nimh.nih.gov/research/research-funded-by-nimh/rdoc/positive-valence-systemsworkshop-proceedings.shtml

NIMH. (2011b). Positive valence systems: Workshop proceedings.

NIMH. (2018). RDoC Changes to the Matrix (CMAT) Workgroup Update : Proposed Positive Valence Domain Revisions. 2018. https://www.nimh.nih.gov/about/advisory-boards-andgroups/namhc/reports/cmat-pvs-report-508_157003.pdf

O’Brien, L., Albert, D., Chein, J., \& Steinberg, L. (2011). Adolescents Prefer More Immediate Rewards When in the Presence of their Peers. Journal of Research on Adolescence, 21(4), 747- 
753. https://doi.org/10.1111/j.1532-7795.2011.00738.x

Olino, T. M., Horton, L. E., \& Versella, M. V. (2016). A comparison of psychometric and convergent validity for social anhedonia and social closeness. Psychological Assessment, 28(11), 14651474. https://doi.org/10.1037/pas0000291

Orchard, F., Pass, L., Marshall, T., \& Reynolds, S. (2017). Clinical characteristics of adolescents referred for treatment of depressive disorders. Child and Adolescent Mental Health, 22(2), 6168. https://doi.org/10.1111/camh.12178

Polanczyk, G. V., Salum, G. A., Sugaya, L. S., Caye, A., \& Rohde, L. A. (2015). Annual research review: A meta-analysis of the worldwide prevalence of mental disorders in children and adolescents. Journal of Child Psychology and Psychiatry and Allied Disciplines, 56(3), 345365. https://doi.org/10.1111/jcpp.12381

Reio, T. G. (2010). The threat of common method variance bias to theory building. Human Resource Development Review, 9(4), 405-411. https://doi.org/10.1177/1534484310380331

Rice, F., Riglin, L., Lomax, T., Souter, E., Potter, R., Smith, D. J., Thapar, A. K., \& Thapar, A. (2019). Adolescent and adult differences in major depression symptom profiles. Journal of Affective Disorders, 243, 175-181. https://doi.org/10.1016/j.jad.2018.09.015

Rizvi, S. J., Pizzagalli, D. A., Sproule, B. A., \& Kennedy, S. H. (2016). Assessing anhedonia in depression: Potentials and pitfalls HHS Public Access. Neurosci Biobehav Rev, 65, 21-35. https://doi.org/10.1016/j.neubiorev.2016.03.004

Rizvi, S. J., Quilty, L. C., Sproule, B. A., Cyriac, A., Michael Bagby, R., \& Kennedy, S. H. (2015). Development and validation of the Dimensional Anhedonia Rating Scale (DARS) in a community sample and individuals with major depression. Psychiatry Research, 229(1-2), 109119. https://doi.org/10.1016/j.psychres.2015.07.062

Rømer Thomsen, K., Whybrow, P. C., \& Kringelbach, M. L. (2015). Reconceptualizing anhedonia: novel perspectives on balancing the pleasure networks in the human brain. Frontiers in Behavioral Neuroscience, 9(March), 49. https://doi.org/10.3389/fnbeh.2015.00049

Rzepa, E., Fisk, J., \& McCabe, C. (2017). Blunted neural response to anticipation, effort and consummation of reward and aversion in adolescents with depression symptomatology. Journal 
of Psychopharmacology, 31(3), 303-311. https://doi.org/10.1177/0269881116681416

Rzepa, E., \& McCabe, C. (2019). Dimensional anhedonia and the adolescent brain: reward and aversion anticipation, effort and consummation. BJPsych Open, 5(6), 1-9. https://doi.org/10.1192/bjo.2019.68

Shulman, E. P., Smith, A. R., Silva, K., Icenogle, G., Duell, N., Chein, J., \& Steinberg, L. (2016). The dual systems model: Review, reappraisal, and reaffirmation. Developmental Cognitive Neuroscience, 17, 103-117. https://doi.org/10.1016/j.dcn.2015.12.010

Snaith, R. P., Hamilton, M., Morley, S., Humayan, A., Hargreaves, D., \& Trigwell, P. (1995). A scale for the assessment of hedonic tone. The Snaith-Hamilton Pleasure Scale. British Journal of Psychiatry, 167, 99-103. https://doi.org/10.1192/bjp.167.1.99

Somerville, L. H., Jones, R. M., \& Casey, B. J. (2010). A time of change: Behavioral and neural correlates of adolescent sensitivity to appetitive and aversive environmental cues. Brain and Cognition, 72(1), 124-133. https://doi.org/10.1016/j.bandc.2009.07.003

Spaeth, M., Weichold, K., \& Silbereisen, R. K. (2015). The development of leisure boredom in early adolescence: Predictors and longitudinal associations with delinquency and depression.

Developmental Psychology, 51(10), 1380-1394. https://doi.org/10.1037/a0039480

Spence S.H. (1997) Structure of anxiety symptoms among children: a confirmatory factor-analytic study. Journal of Abnormal Psychology, 106(2), 280-297, DOI: 10.1037//0021-843x.106.2.280

Spitzer RL Kroenke K Williams JB et al. (2006). A brief measure for assessing generalized anxiety disorder: the GAD-7. Arch Intern Med;166:1092-1097.

Steinberg, L. (2004). Risk Taking in Adolescence What Changes, and Why? Annals of the New York Academy of Sciences, 1021, 51-58.

Tabachnick, B. G., \& Fidell, L. S. (2014). Using multivariate statistics. Harlow.

Taubitz, L. E., Pedersen, W. S., \& Larson, C. L. (2015). BAS Reward Responsiveness: A unique predictor of positive psychological functioning. Personality and individual differences, 80, 107-112. Thomsen, K. R. (2015). Measuring anhedonia: impaired ability to pursue, experience, and learn about reward. Frontiers in Psychology, 6. https://doi.org/10.3389/fpsyg.2015.01409

van Roekel, E., Bennik, E. C., Bastiaansen, J. A., Verhagen, M., Ormel, J., Engels, R. C. M. E., \& 
Oldehinkel, A. J. (2016). Depressive Symptoms and the Experience of Pleasure in Daily Life: An Exploration of Associations in Early and Late Adolescence. Journal of Abnormal Child Psychology, 44(5), 999-1009. https://doi.org/10.1007/s10802-015-0090-z

Watson, D., \& Clark, L. A. (1994). The PANAS-X: Manual for the Positive and Negative Affect Schedule-Expanded Form. Ames: The University of Iowa.

Watson, R., Harvey, K., McCabe, C., \& Reynolds, S. (2020). Understanding anhedonia: a qualitative study exploring loss of interest and pleasure in adolescent depression. European Child and Adolescent Psychiatry, 29(4), 489-499. https://doi.org/10.1007/s00787-019-01364-y

Wood, A., Kroll, L., Moore, A., \& Harrington, R. (1995). Properties of the mood and feelings questionnaire in adolescent psychiatric outpatients: a research note. Journal of Child Psychology and Psychiatry, and Allied Disciplines, 36(2), 327-334. https://doi.org/10.1111/j.14697610.1995.tb01828.x

Wu, H., Mata, J., Thompson, R. J., Furman, D. J., Whitmer, A. J., \& Gotlib, I. H. (2017). Anticipatory and consummatory pleasure and displeasure in major depressive disorder: An experience sampling study. Journal of Abnormal Psychology, 126(2), 149-159.

https://doi.org/10.1037/abn0000244 


\section{Appendix. The Anhedonia Scale for Adolescents (ASA)}

This questionnaire is about how interesting and enjoyable you have found your life over the past two weeks. Please answer all the questions as honestly as possible. Please circle how often you experienced the feeling, thought or behaviour described in each sentence. Your options are: NEVER (0) SOMETIMES (1) OFTEN (2) ALWAYS (3)

1. I had no motivation to get started on things

2. Nothing made me feel excited

3. I should have been enjoying things, but I couldn't

4. I felt detached from other people

5. I did not look forward to anything

6. Nothing felt fun or enjoyable

7. I couldn't see myself enjoying things in the future

8. I felt enthusiastic

9. I did not want to do anything

10. I pretended things excited me, but actually I found them boring

11. I felt connected to the world around me

12. I did not feel any emotion

13. Everything felt like a lot of effort to do

14. I felt like my life had meaning and purpose

Over the past two weeks, how often did you not feel positive? Please circle?

NONE SEVERAL DAYS MORE THAN HALF THE DAYS ALMOST EVERY DAY

Scoring: This is the suggested order for administering the scale. A higher score indicates greater levels of anhedonia (/42). Subscale 1: enjoyment, excitement and emotional flattening: 2, 3, 4, 6, 7, 10, 12; Subscale 2: enthusiasm, connection and purpose: $8,11,14$; Subscale 3: effort, motivation and drive: 1, 5, 9, 13. 